LBNL-49504

\title{
Realized and Prospective Impacts of U.S. Energy Efficiency Standards for Residential Appliances
}

\author{
Stephen Meyers, James McMahon, Michael McNeil, Xiaomin Liu
}

\author{
Environmental Energy Technologies Division \\ Lawrence Berkeley National Laboratory \\ University of California \\ Berkeley, CA 94720
}

June 2002

\section{FINAL REPORT}

This work was supported by the Assistant Secretary for Energy Efficiency and Renewable Energy, Office of Building Technologies of the U.S. Department of Energy under Contract No. DE-AC03-76SF00098. 


\section{TABLE OF CONTENTS}

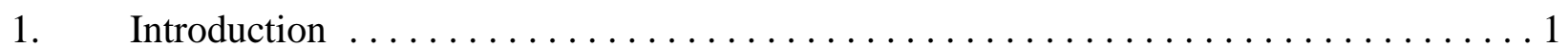

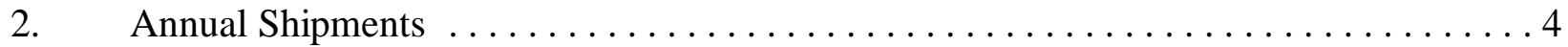

3. Average Annual Energy Use or Energy Efficiency $\ldots \ldots \ldots \ldots \ldots \ldots \ldots \ldots \ldots \ldots 11$

4. Appliance Prices and Incremental Costs of Standards . . . . . . . . . . . . . . . 21

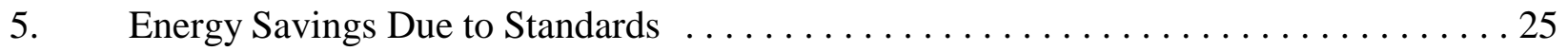

6. National Consumer Costs and Benefits Due to Appliance Standards . . . . . . . . . . 35

7. Carbon Dioxide Emissions Reduction Due to Standards . . . . . . . . . . . . . 39

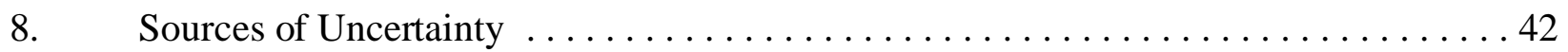

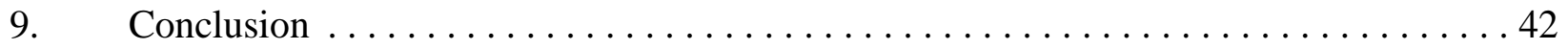

APPENDIX 1 Technical Support Documents for DOE Residential Energy Efficiency

Standards ............................ 43 


\section{ABBREVIATIONS AND ACRONYMS}

$\begin{array}{ll}\text { AAUE } & \text { Average annual energy use } \\ \text { AFUE } & \text { Average fuel utilization efficiency } \\ \text { AHAM } & \text { Association of Home Appliance Manufacturers } \\ \text { ARI } & \text { Air-Conditioning and Refrigeration Institute } \\ \text { LBNL } & \text { Lawrence Berkeley National Laboratory } \\ \text { NPV } & \text { Net Present Value } \\ \text { TSD } & \text { Technical Support Document }\end{array}$




\section{ACKNOWLEDGMENTS}

This study built upon past work at LBNL by Sachu Constantine and Johanna Kollar. Peter Biermayer, Jim Lutz, and Greg Rosenquist provided assistance with specific products, and Peter Chan assisted as well. Helpful comments were provided by Jim Lutz, Steve Wiel, and Andrew Nicholls of PNL. Diana Morris assisted with production. 


\begin{abstract}
This study estimated energy, environmental and consumer economic impacts of U.S. Federal residential energy efficiency standards that became effective in the 1988-2001 period or will take effect by the end of 2007. These standards have been the subject of in-depth analyses conducted as part of DOE's standards rulemaking process. This study drew on those analyses, but updated certain data and developed a common framework and assumptions for all of the products. We estimate that the considered standards will reduce residential primary energy consumption and $\mathrm{CO}_{2}$ emissions in 2020 by $8-9 \%$ compared to the levels expected without any standards. They will save a cumulative total of 25-30 quads by the year 2015, and 60 quads by 2030. The estimated cumulative net present value of consumer benefit amounts to nearly $\$ 80$ billion by 2015 , and grows to $\$ 130$ billion by 2030 . The overall benefit/cost ratio of cumulative consumer impacts in the 1987-2050 period is 2.75:1. The cumulative cost of DOE's program to establish and implement the standards is in the range of \$200-250 million.
\end{abstract}




\section{Introduction}

The primary purpose of this project was to construct a common analytical framework to estimate energy, environmental, and consumer economic impacts of Federal residential energy efficiency standards that became effective in the 1988-2001 period or will take effect by the end of 2007. This study considered initial (NAECA) standards and updates for nine different products (Table 1-1). ${ }^{1}$ These standards have been the subject of in-depth analyses conducted by Lawrence Berkeley National Laboratory (LBNL) as part of DOE's standard rulemaking process. The results of these individual analyses have been published in a number of Technical Support Documents (TSDs). Appendix 1 presents a listing of these TSDs.

This project differed from the in-depth analyses done for the TSDs in many ways (apart from being greatly simplified):

- The TSD analyses estimated prospective impacts only, whereas this study estimated both realized (through 2000) and prospective impacts (through 2050).

- The TSD analyses were performed at different times over the past 13 years and thus considered product installations and impacts over varying periods. For all products, this study considers installations through 2030 and impacts through $2050 .^{2}$

- $\quad$ Each TSD analysis used forecasts of product shipments and energy prices that were current at the time. This study used recent data on actual product shipments and energy prices to calculate realized savings. To estimate prospective impacts, we developed new projections of product shipments based on recent trends and appliance industry near-term forecasts. We also used the latest DOE/EIA projections of future energy prices (EIA, 2001).

- The TSD analyses have varied in their specification of a base case efficiency trend against which the impact of standards was evaluated. In some of the analyses in recent years, the base case incorporates an expectation of improvement in energy efficiency without a standard, but in earlier years the base case reflected no change over time in efficiency. This study used a dynamic base case for all products, and adopted the perspective that

\footnotetext{
${ }^{1}$ We did not analyze the impact of standards for oil furnaces and boilers, kitchen ranges and ovens, direct heating equipment (wall, floor, and room heaters), and swimming pool heaters. Based on limited available data, it appears that these standards had a relatively small impact on the market. This study also did not analyze standards for products in commercial buildings, such as fluorescent lamp ballasts or commercial HVAC.

${ }^{2}$ Appliances have useful lifetimes of 10-20 years. In order to capture the lifetime energy savings of products purchased in the 2020-2030 period, we consider impacts through 2050.
} 
manufacturers would have made improvements in energy efficiency without standards in most cases.

\section{Overview of Methodology for This Study}

We developed a spreadsheet accounting model to calculate national energy savings and consumer benefits for each product. The analysis tracks shipments of a given product in each year, beginning in the late 1980s and ending in 2030. The key energy-use variable is the average annual energy use or energy efficiency of a given product sold in each year. A key consumer impact variable is the average product price in each year.

Other input data are the average residential price of electricity and natural gas in each year (used to calculate the dollar value of energy savings), and factors for converting site energy to primary energy consumption.

For each of the above, we used actual data where available and made (or adopted from the TSDs) projections of future trends through 2030. For average energy use/efficiency and product price, we made projections of trends under alternative scenarios in order to estimate the impact of specific standards and updates.

The approach for estimating impacts of standards involves creating a base case scenario that assumes no standards were or will be implemented, and then comparing various scenarios with standards to the base case.

Each section below further describes the data sources and assumptions used.

\section{References}

Energy Information Administration (2001). Annual Energy Outlook 2002, U.S. Department of Energy, Washington, D.C. 
Table 1-1

U.S. DOE Energy Efficiency Standards

for Residential Appliances and Equipment

\begin{tabular}{|l|l|l|l|l|l|l|l|l|l|l|l|l|l|l|l|l|l|l|l|l|}
\hline Product & \multicolumn{7}{|c|}{ Date Effective } \\
\hline & 88 & 89 & 90 & 91 & 92 & 93 & 94 & 95 & 96 & 97 & 98 & 99 & 00 & 01 & 02 & 03 & 04 & 05 & 06 & 07 \\
\hline Refrigerators & & & $\mathrm{X}$ & & & $\mathrm{X}$ & & & & & & & & $\mathrm{X}$ & & & & & & \\
\hline Freezers & & & $\mathrm{X}$ & & & $\mathrm{X}$ & & & & & & & & $\mathrm{X}$ & & & & & & \\
\hline Room Air Conditioners & & & $\mathrm{X}$ & & & & & & & & & & $\mathrm{X}$ & & & & & & & \\
\hline Central ACs and Heat Pumps & & & & & $\mathrm{X}$ & & & & & & & & & & & & & & $\mathrm{X}$ & \\
\hline Clothes Washers & $\mathrm{X}$ & & & & & & $\mathrm{X}$ & & & & & & & & & & $\mathrm{X}$ & & & $\mathrm{X}$ \\
\hline Clothes Dryers & $\mathrm{X}$ & & & & & & $\mathrm{X}$ & & & & & & & & & & & & & \\
\hline Dishwashers & $\mathrm{X}$ & & & & & & $\mathrm{X}$ & & & & & & & & & & & & & \\
\hline Water Heaters & & & $\mathrm{X}$ & & & & & & & & & & & & & & $\mathrm{X}$ & & & \\
\hline Gas Furnaces & & & & & $\mathrm{X}$ & & & & & & & & & & & & & & \\
\hline Oil Furnaces & & & & & $\mathrm{O}$ & & & & & & & & & & & & & & & \\
\hline Ranges and Ovens & & & $\mathrm{O}$ & & & & & & & & & & & & & & & & & \\
\hline Pool Heaters & & & $\mathrm{O}$ & & & & & & & & & & & & & & & & & \\
\hline Direct Heating Equipment & & & $\mathrm{O}$ & & & & & & & & & & & & & & & \\
\hline
\end{tabular}

$\mathrm{X}=$ Included in this study's estimates

$\mathrm{O}=$ Not included in this study's estimates 


\section{Annual Shipments}

\section{Historical Data}

We used data on annual domestic shipments from industry sources (AHAM, ARI) for all of the considered products for the 1980-2000 period. In the case of central air conditioners and heat pumps, the industry data include single- and three-phase equipment. As the latter are generally not used in residential applications, LBNL estimated the share of single-phase units for the rulemaking analysis, and we used those data here (see Appendix 1,\#7).

\section{Projections for 2001-2030}

The projections used in the previous technical analyses were made during the rulemaking process for each product. For this study, we prepared new projections that take into account the actual data through the year 2000. In most cases, shipments in this period were greater than had been estimated due to the substantial growth in disposable income in this period. Although the growth in installations seen in this period is not expected to continue into the future, it does call for some adjustment to the projections made for the TSDs for most products. (Revisions of projections were not necessary for water heaters and gas furnaces.)

In making revised projections, we reduced forecasts made by AHAM for 2001-02 by 5\%. AHAM's forecasts (based on input from manufacturers) were made in May 2001. In light of the economic outlook as of the end of 2001, they are too optimistic regarding economic growth. For 2003-2030, we applied the annual percentage growth in each year from the most recent TSD projections. In the case of clothes dryers, for which there were no recent projections, we used the projected annual growth in clothes washer shipments as a proxy for clothes dryer shipments. In all cases where we made revised projections, the forecast shipments are considerably higher than in the TSDs.

In the TSDs for some products, the projection of shipments is lower with standards than without them, as the analysis predicts that the higher price will lead to fewer purchases. The methodology has a module for adjusting energy consumption in the "no standards" case to account for products that would be kept in use if a new product were not purchased. The simpler framework used in this study does not have that capability, and using a lower shipments projection in the standards cases would result in overstatement of energy savings. Thus, we use the "no standards" projections in all cases. In the case of water heaters, projected shipments are greater in the 2004 standards case than in the base case for gas water heaters, and lower for electric water heaters in the standards case. Thus, we separately accounted for the impacts of fuel switching using the shipments projections in the water heater TSD. 


\section{References}

Association of Home Appliance Manufacturers, 1999 (1997, 95, 93 87). Major Appliance Industry Fact Book. Chicago, IL.

Air-Conditioning and Refrigeration Institute, 1999. Statistical Profile of the Air-Conditioning, Refrigeration, and Heating Industry.. Arlington, VA. 


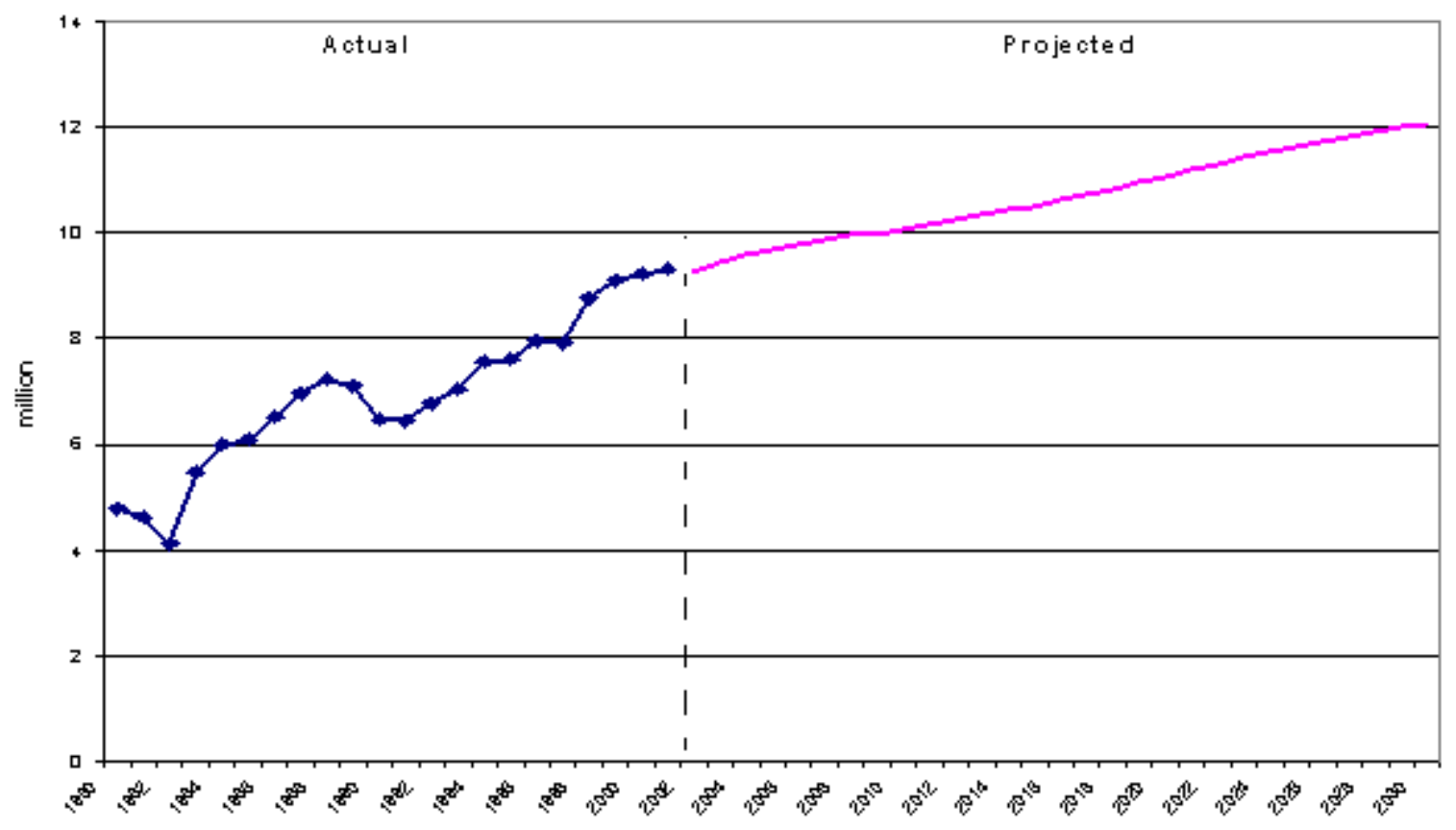

Figure 2.1 New Refrigerators - Annual Shipments, 1980-2030

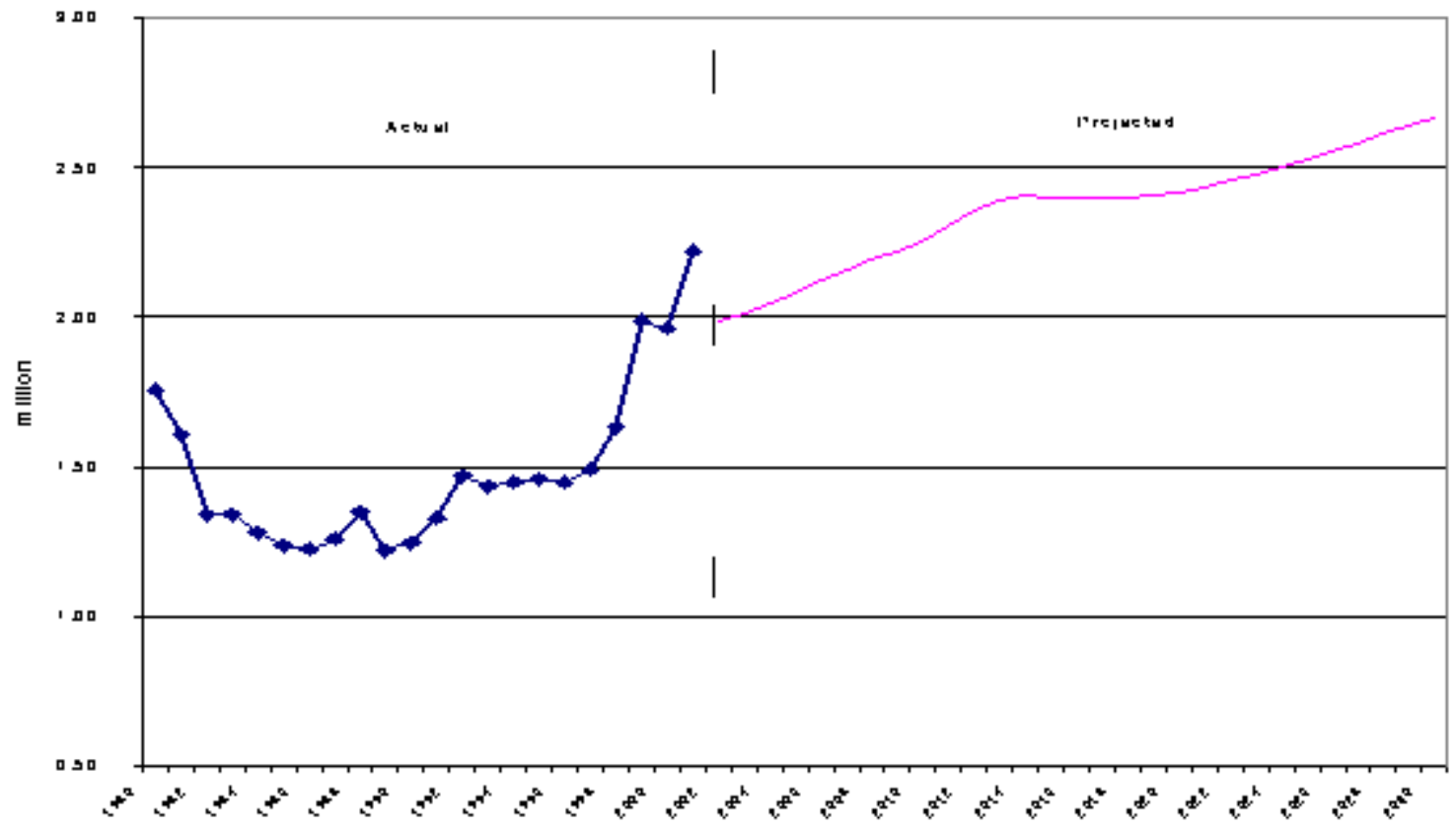

Figure 2.2 New Freezers - Annual Shipments, 1980-2030

6 


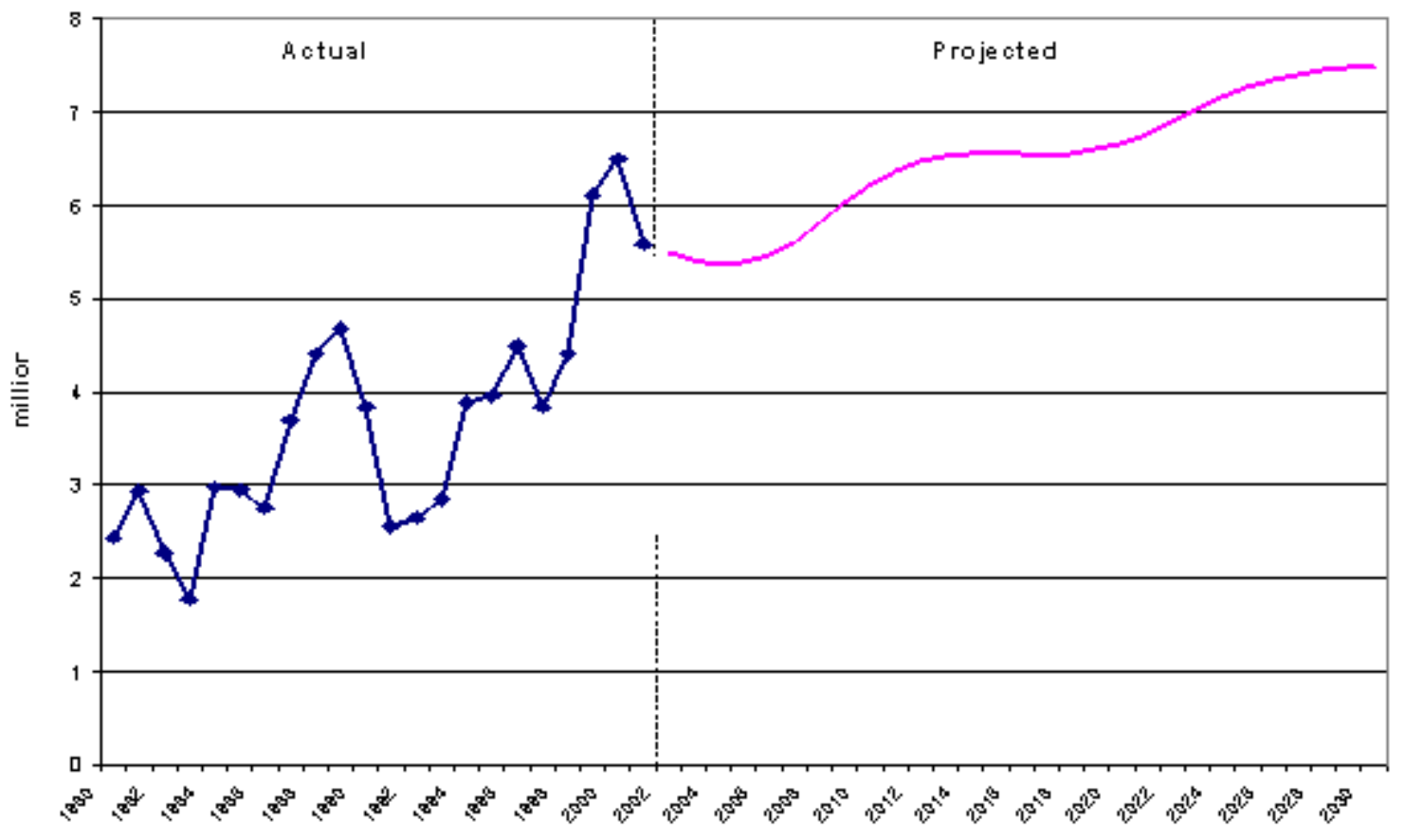

Figure 2.3 New Room Air Conditioners - Annual Shipments, 1980-2030

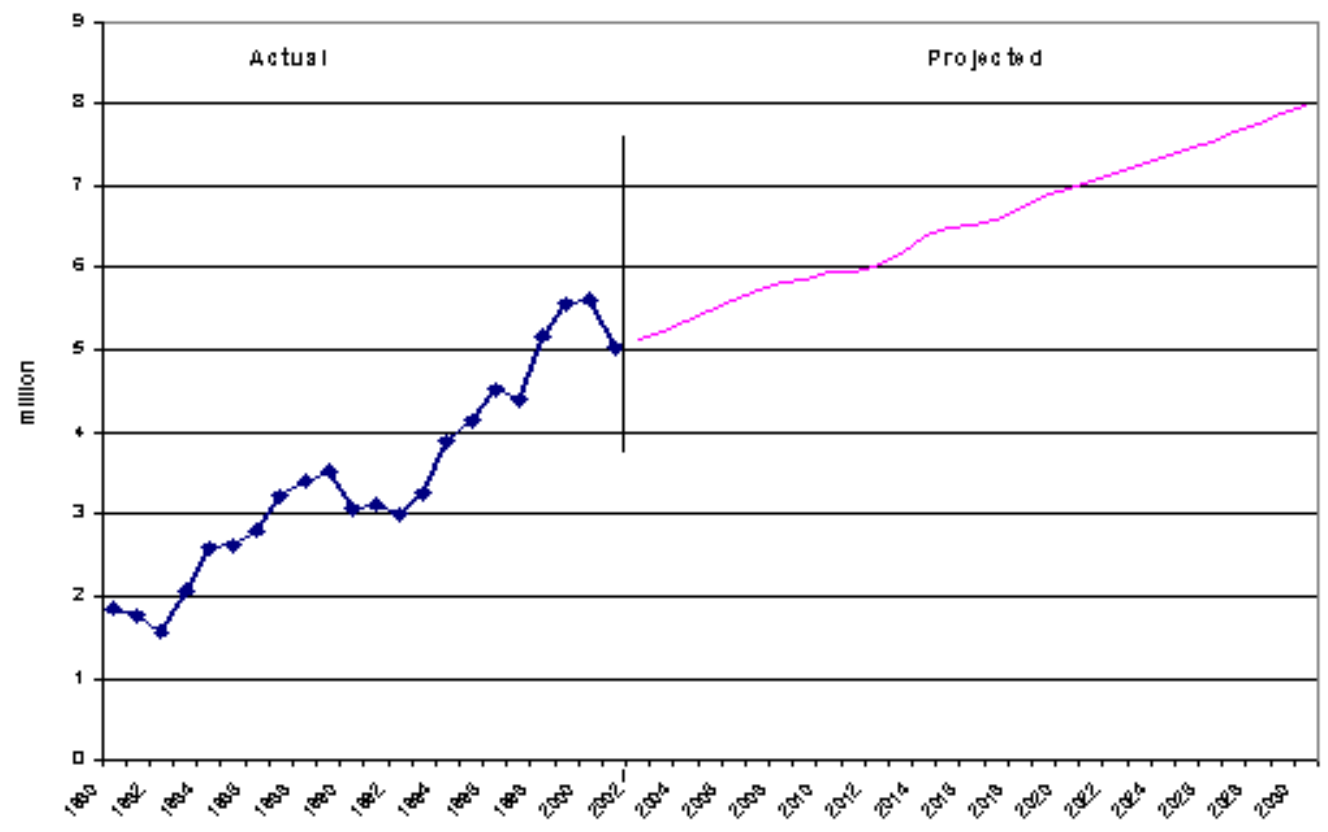

Figure 2.4 New Central Air Conditioners \& Heat Pumps - Annual Shipments, 19802030 


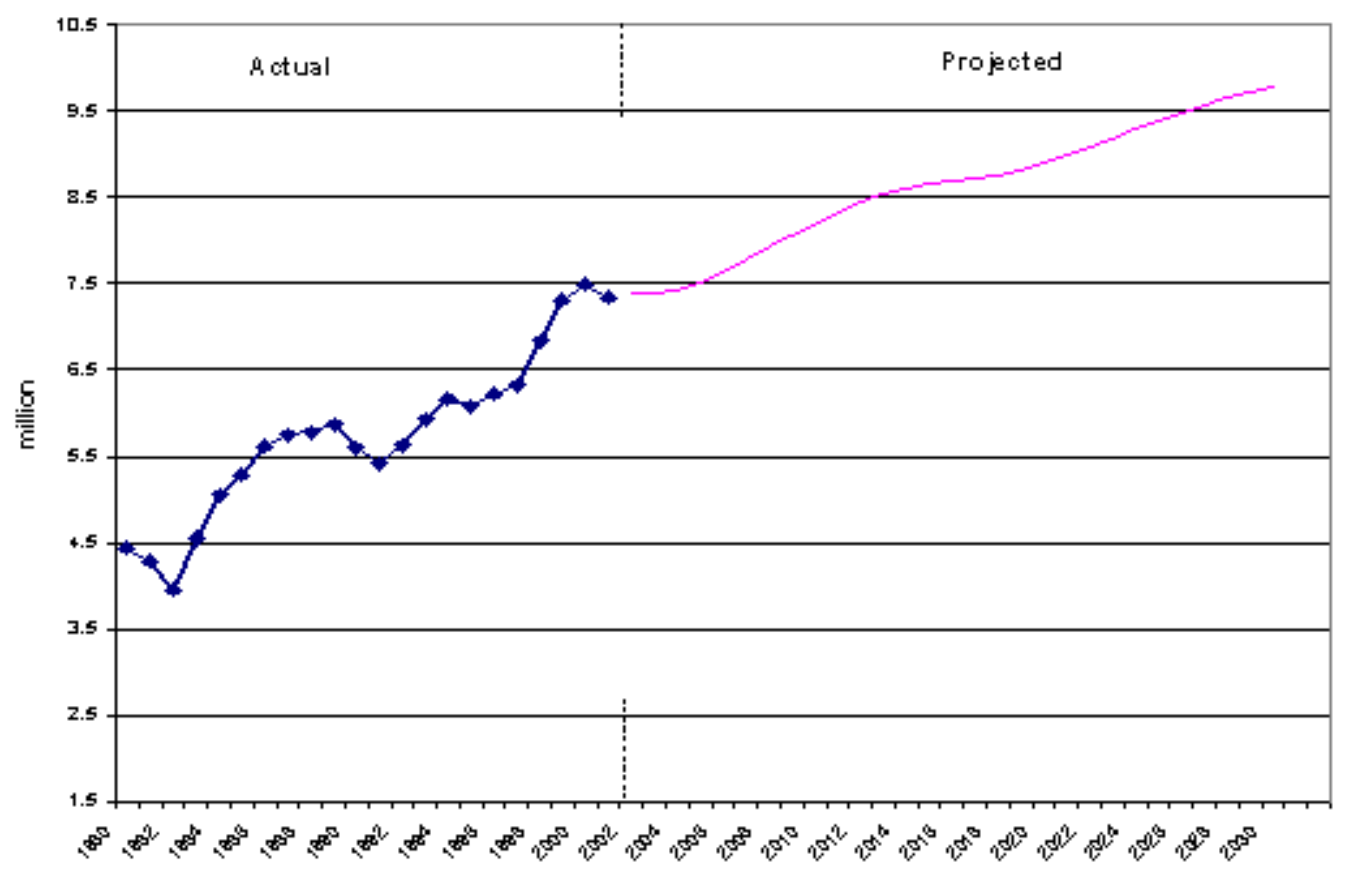

Figure 2.5 New Clothes Washers - Annual Shipments, 1980-2030

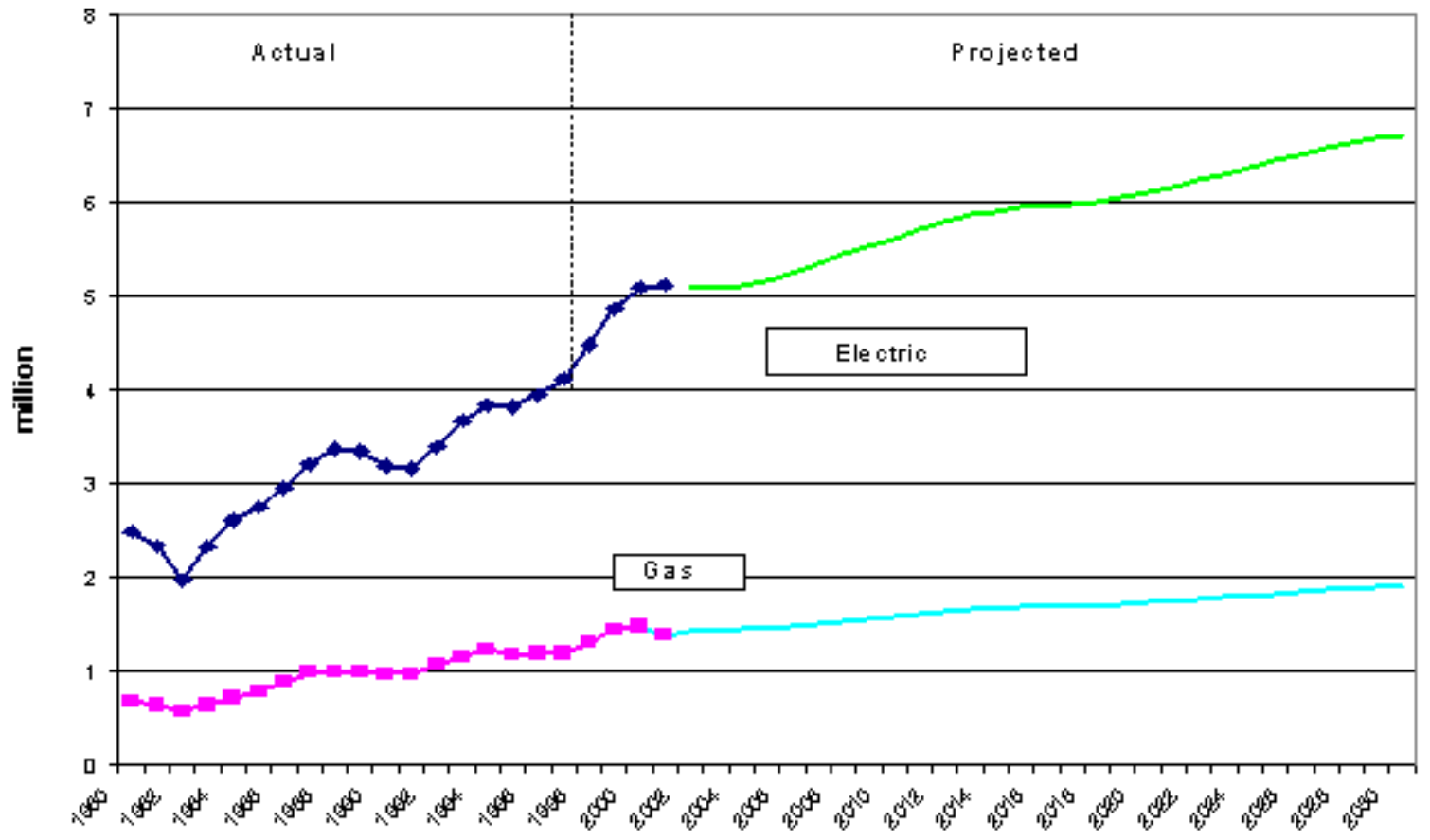

Figure 2.6 New Clothes Dryers - Annual Shipments, 1980-2030

8 


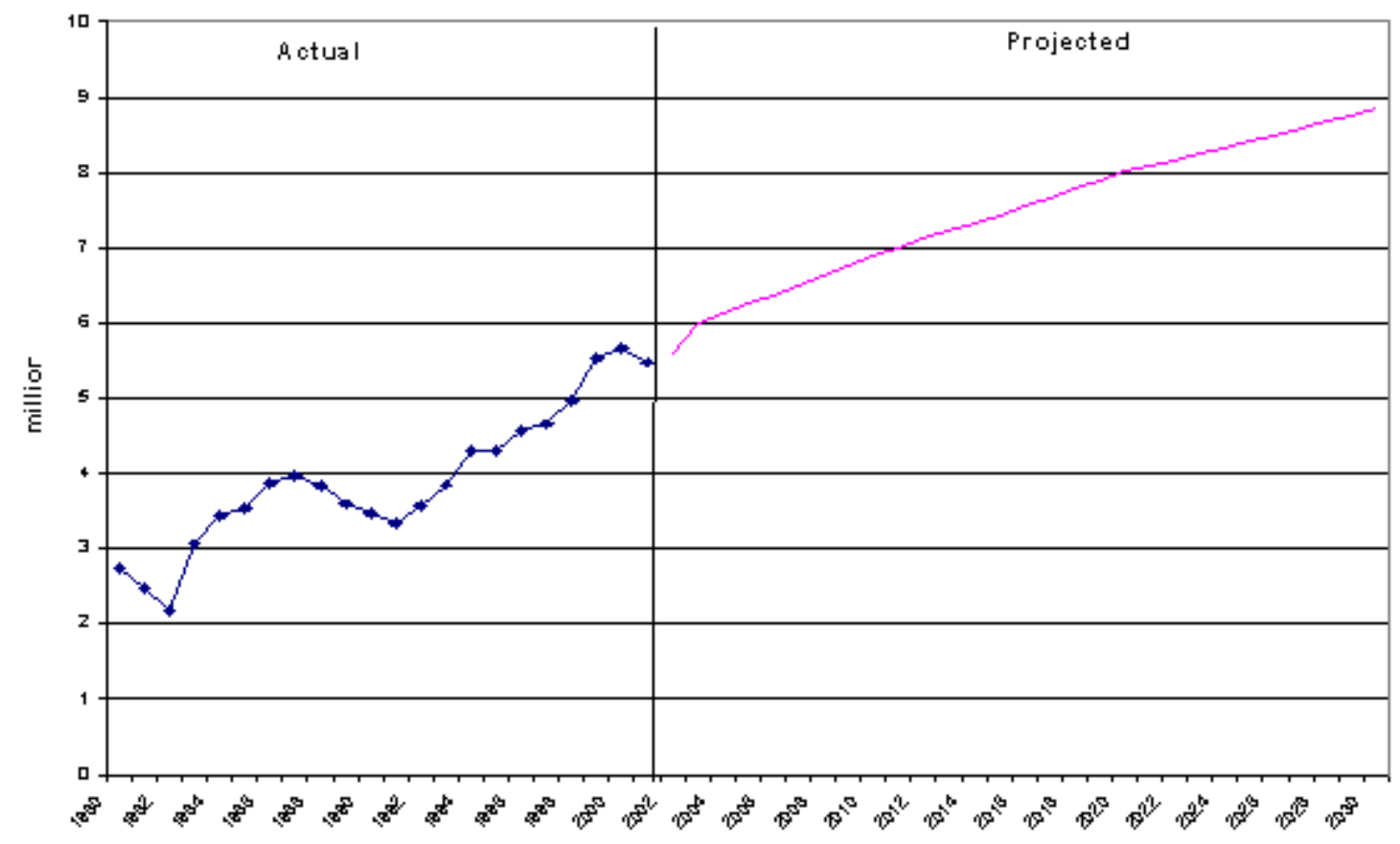

Figure 2.7 New Dishwashers - Annual Shipments, 1980-2030

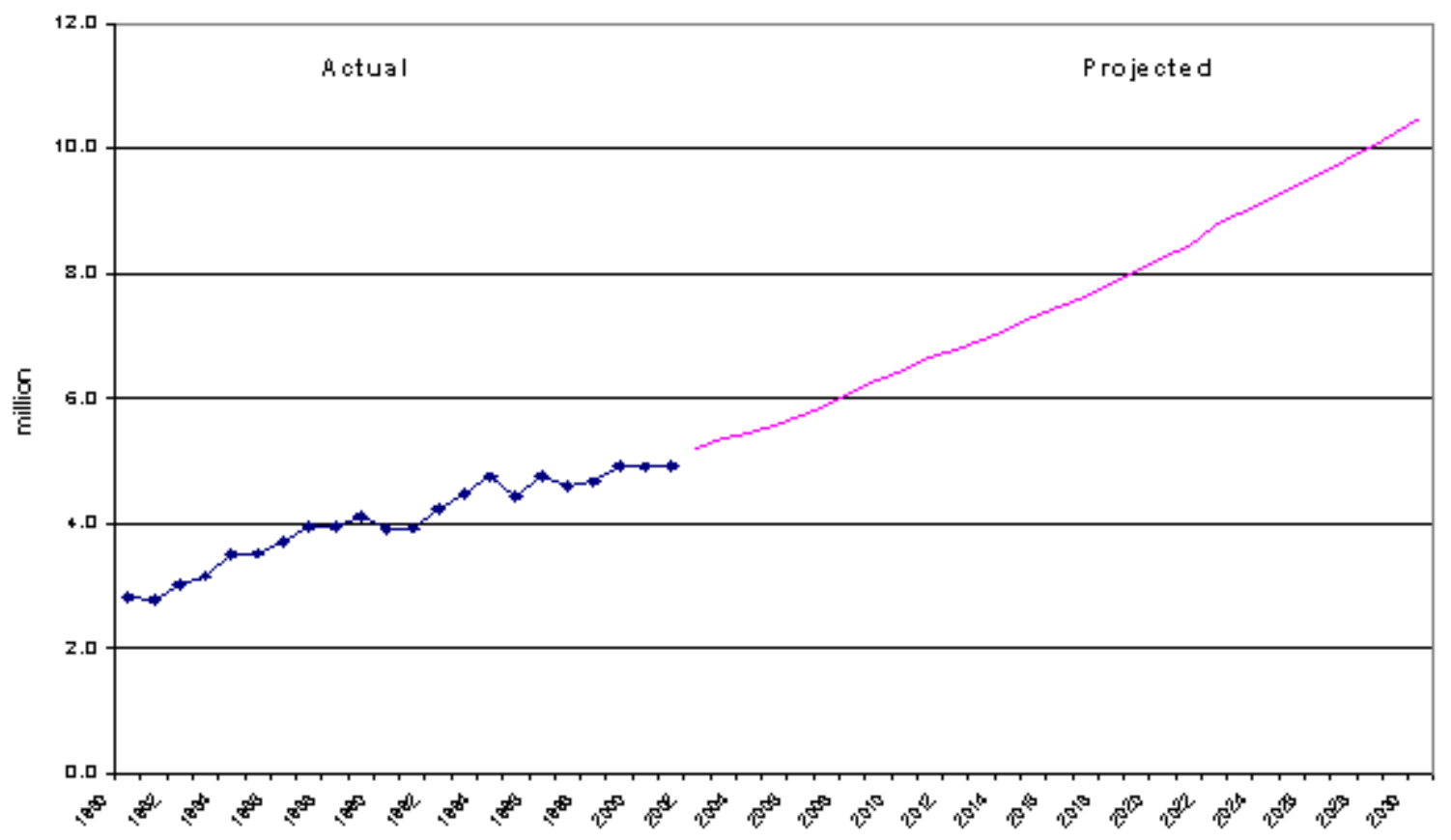

Figure 2.8 New Gas Water Heaters - Annual Shipments, 1980-2030 


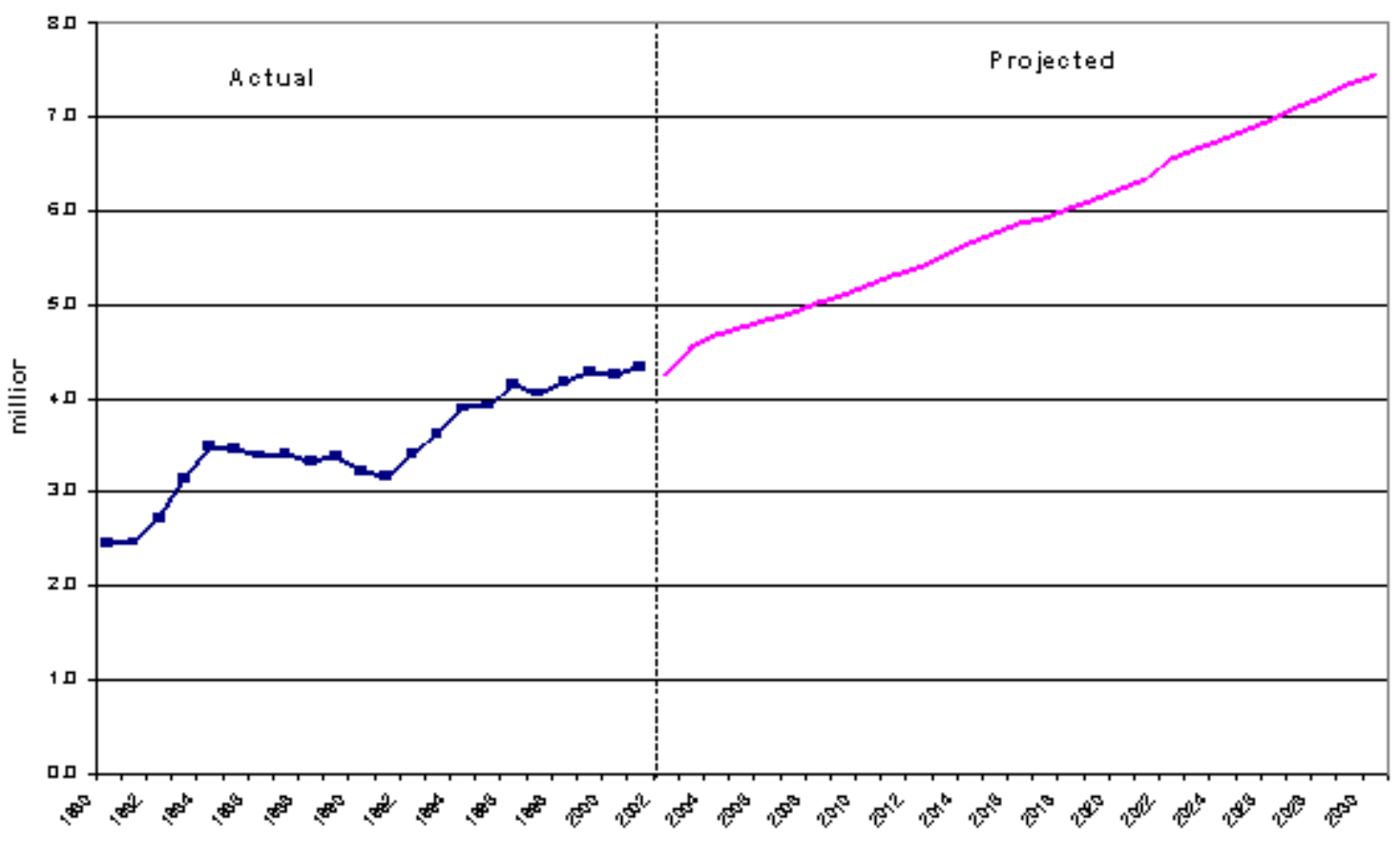

Figure 2.9 New Electric Water Heaters - Annual Shipments, 1980-2030

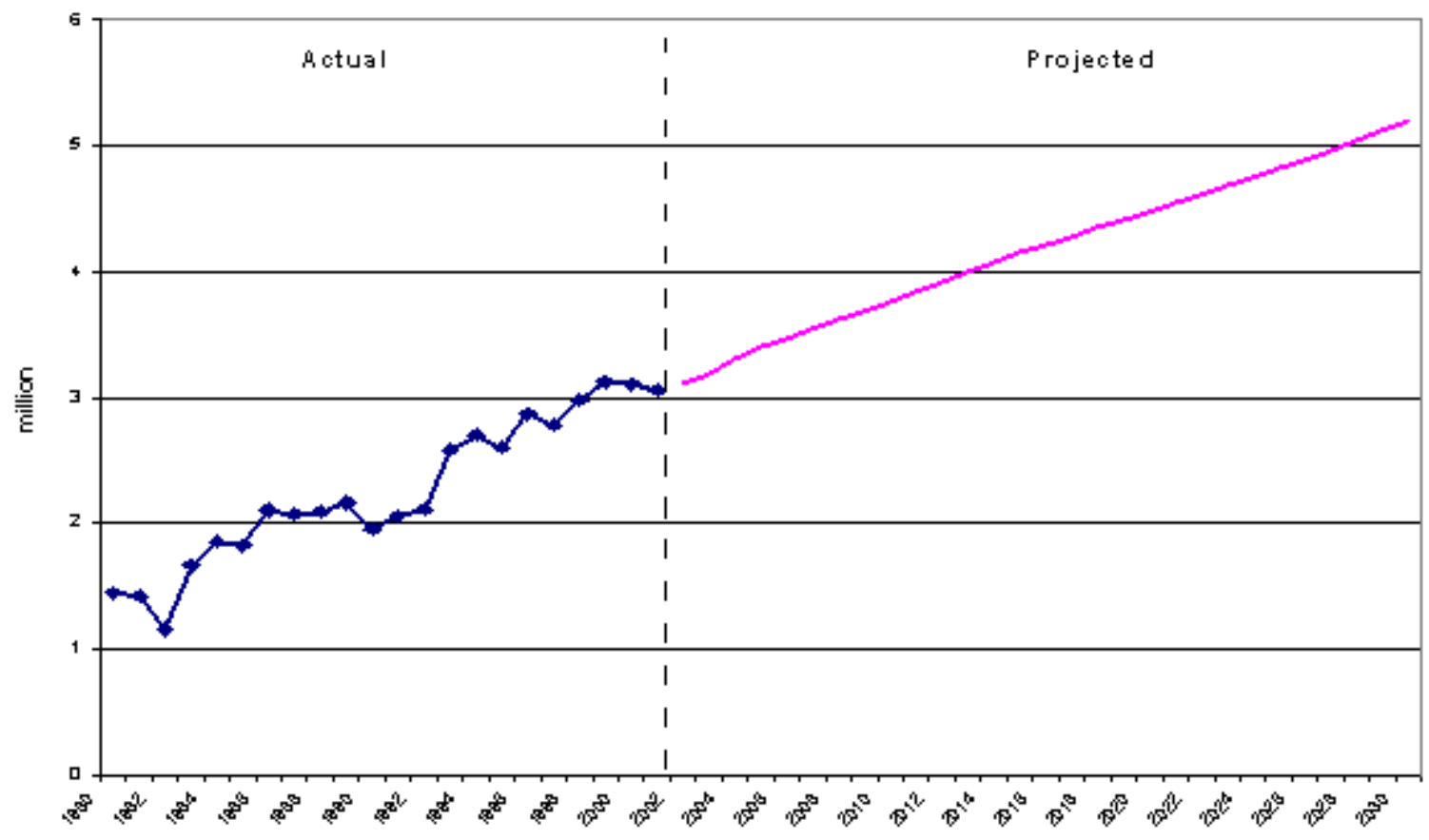

Figure 2.10 New Gas Furnaces - Annual Shipments, 1980-2030 


\section{Average Annual Energy Use or Energy Efficiency}

\section{Historical Data}

Industry sources have published estimates of average annual energy use (AAEU) or energy efficiency of products sold in a given year in a consistent manner over time for the following products:

- Refrigerators (AHAM)

- Freezers (AHAM)

- Room Air Conditioners (AHAM)

- Clothes Washers (AHAM) ${ }^{3}$

- Dishwashers (AHAM)

- Central Air Conditioners \& Heat Pumps (ARI)

For gas furnaces, historical estimates of the average fuel utilization efficiency (AFUE) of products sold in a given year were made for a number of years in the period 1980-1995, based on industry data (Wenzel et al., 1997).

For water heaters and clothes dryers, historical estimates of AAEU of products sold in a given year are not available from industry sources. In these cases, we utilized the estimates made in the respective TSDs.

\section{Scenarios}

For each product, we developed a base case that envisions likely trends without DOE energy efficiency standards. The initial years are based on actual values, where available. We then made a subjective estimate as to how AAEU (or energy efficiency) might have evolved if no standard had been implemented. We based the estimate on the historical trend, where available, along with judgement as to technical changes that might have been introduced by manufacturers that would improve energy efficiency. Non-regulatory factors that contribute to efficiency increases in the base case include government and private $\mathrm{R} \& \mathrm{D}$, utility and state demand-side programs, and consumer information and labelling programs (such as Energy Guide and Energy Star).

For each product, we developed separate scenarios for the initial standard and for each update. The scenario for the initial standard assumes that no updates were implemented afterward. These scenarios also make use of historic data to estimate a trend for future years.

\footnotetext{
${ }^{3}$ For clothes washers, we did not use the industry estimates directly because they reflect different assumptions concerning hot water inlet temperature than the TSD analysis. However, the trend in the data from the TSD is very similar to the industry estimates.
} 
For the updates taking effect in 2000 and later, we first derived the AAEU or energy efficiency from the TSD engineering estimates for products that just meet the standard. We then estimated the average value in the market, assuming that some share of the shipments has better efficiency than the minimum required. We assume this value remains constant over time.

In most cases, we assumed that the impact of a given standard begins in the year corresponding to the legal implementation date. In some cases, however, the historic data suggest that manufacturers began to market products meeting a standard one or more years in advance of the implementation date. In these cases (noted below) we began the standard scenario before the implementation date.

The value for any given year refers to the AAEU or energy efficiency of products sold in that year. The calculations assume that the original value for a given annual cohort remains constant for all years in which those units continue to operate.

\section{Notes}

\section{Refrigerators and Freezers}

We assume the impact of the NAECA 1990 standard began in 1987. The standard was announced in 1986, and the decline in the actual AAEU beginning in 1987 suggests that manufacturers began improving energy efficiency in preparation for the NAECA standard. Similarly, in the case of refrigerators, we assume the impact of the 1993 update begins in 1992, and that the impact of the 2001 update begins in 2000. The AAEU values for the 2001 update for both products are based on the published regulations for various product classes and the relative distribution of shipments in 1996.

\section{Room Air Conditioners}

We assume the impact of the NAECA 1990 standard began in 1987. The standard was announced in 1986, and the increase in the actual Energy Efficiency Ratio (EER) beginning in 1987 suggests that manufacturers began improving energy efficiency in preparation for the NAECA standard. The value for the 2001 update is based on the minimum levels for various product types and the relative distribution of shipments in 1994.

\section{Central Air Conditioners}

The value used for the 2006 update is SEER (Seasonal EER) 12. 


\section{Clothes Washers}

The values include electricity use by the clothes washer as well as the estimated energy use for clothes drying and for heating the water for the washer. ${ }^{4}$ (The values in Figure 3.5 assume that the clothes dryer and water heater use electricity, but our model accounts for the respective market shares claimed by gas and electric dryers and water heaters. In the overall analysis, we accounted for gas-fired water heaters and clothes dryers.) Nearly all of the values are based on the TSD. For this study, we estimated a slight change after 1993 in the base case, as there was little to support a downward trend in average energy use in the historical data. As the initial (1988) NAECA standard had little if any impact on the market, we include it in the base case.

\section{Clothes Dryers}

The values for the base case and the 1994 standard scenarios are based on LBNL technical analyses, with adjustment to 359 cycles per year. The historical trend before 1990 is uncertain. We assume some market penetration of efficiency-improving features in 1992-93. As the initial (1988) NAECA standard had little if any impact on the market, we include it in the base case.

\section{Dishwashers}

The values include energy use by the dishwasher itself as well as the estimated energy use for heating the water for the dishwasher (the values in the chart assume that the water heater uses electricity). As the initial (1988) NAECA standard had little if any impact on the market, we include it in the base case.

\section{Water Heaters}

The values for the NAECA 1990 standard and 2004 update scenarios are from the TSD. In the absence of data, we estimated that the NAECA standard caused a 5\% reduction in AAEU. The post-1990 base case trend was estimated for this study.

\section{Gas Furnaces}

The AFUE values for 1980-2000 are based on industry data for selected years. We assume some improvement after 1991 in the base case, as the market share of more efficient furnaces was growing even before the standard was implemented (partially in response to commercialization of efficient furnaces after joint DOE/private R\&D).

\footnotetext{
${ }^{4}$ The reason for including dryer energy use is that the 2004 and 2007 standards are based on a modified energy factor that includes the impact of higher spin speed in washers that spin more water out of the clothes and result in less time in the dryer.
} 


\section{References}

Association of Home Appliance Manufacturers, 1999 (1997, 95, 93 87). Major Appliance Industry Fact Book. Chicago, IL.

Air-Conditioning and Refrigeration Institute, 1999. Statistical Profile of the Air-Conditioning, Refrigeration, and Heating Industry.. Arlington, VA.

Wenzel, T., et al., 1997. Energy Data Sourcebook for the U.S. Residential Sector, Lawrence Berkeley National Laboratory Report LBNL-40297, Berkeley, CA. 


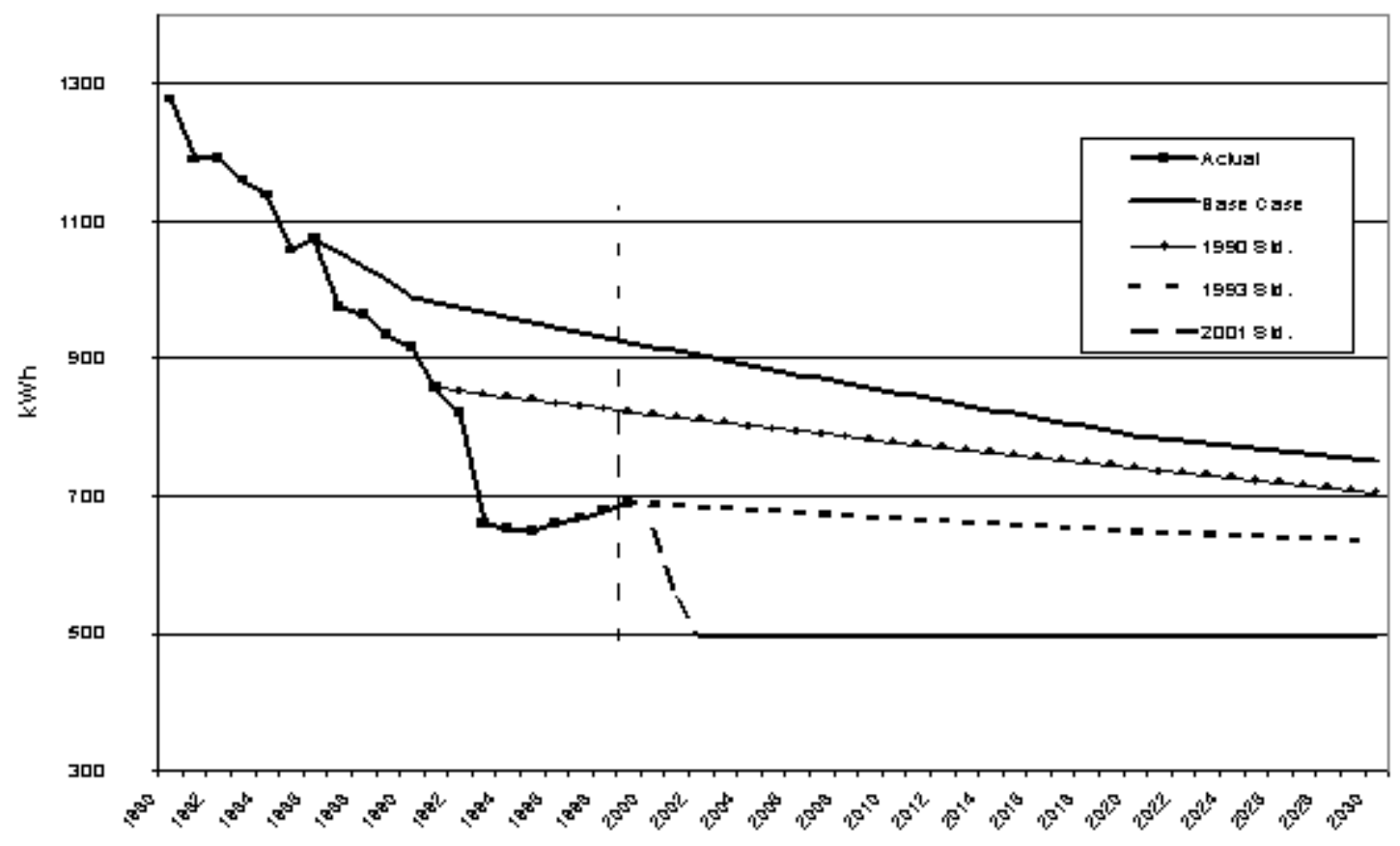

Figure 3.1 New Refrigerators - Average Annual Electricity Use, 1980-2030

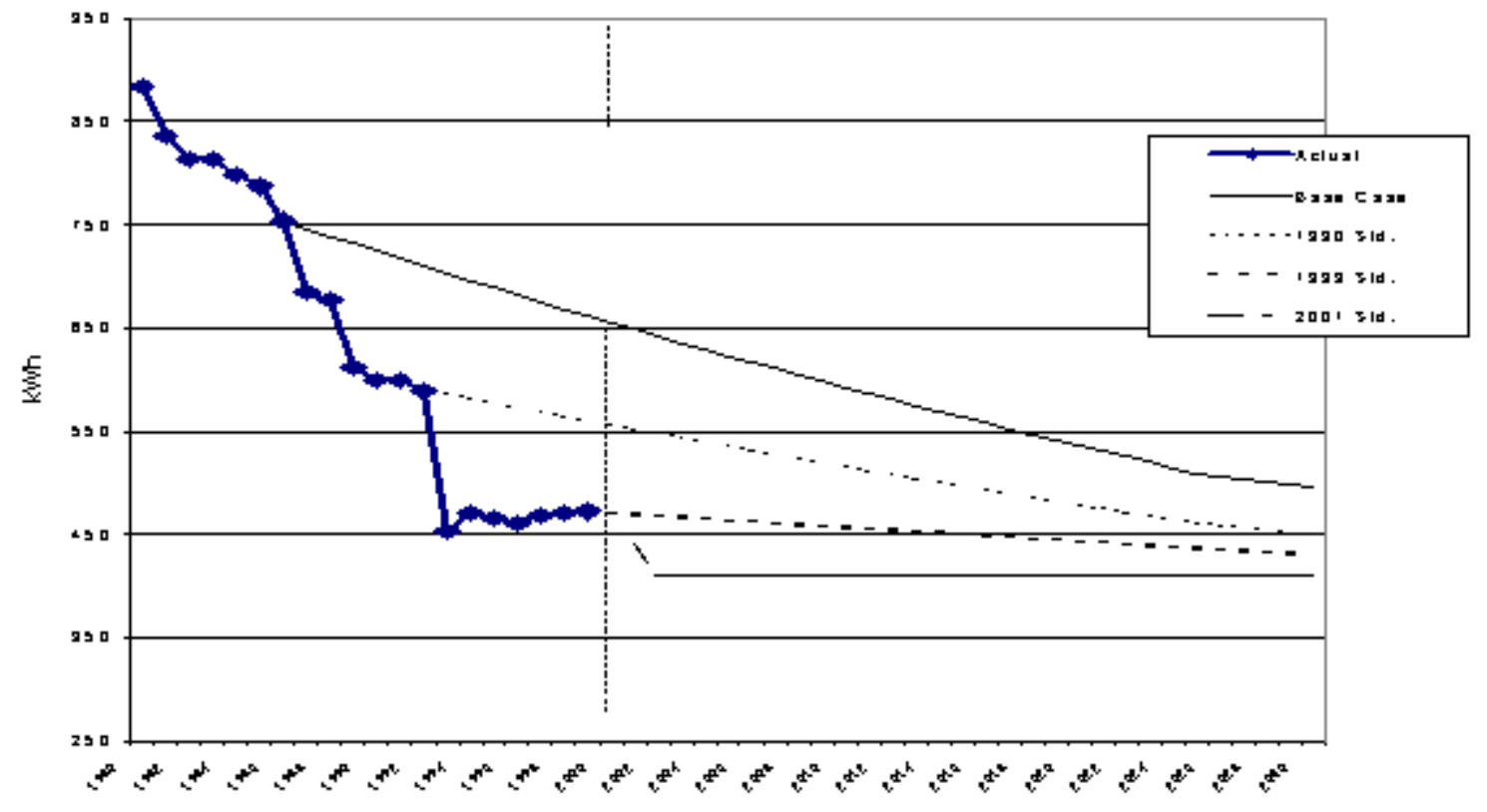

Figure 3.2 New Freezers - Average Annual Electricity Use, 1980-2030

15 


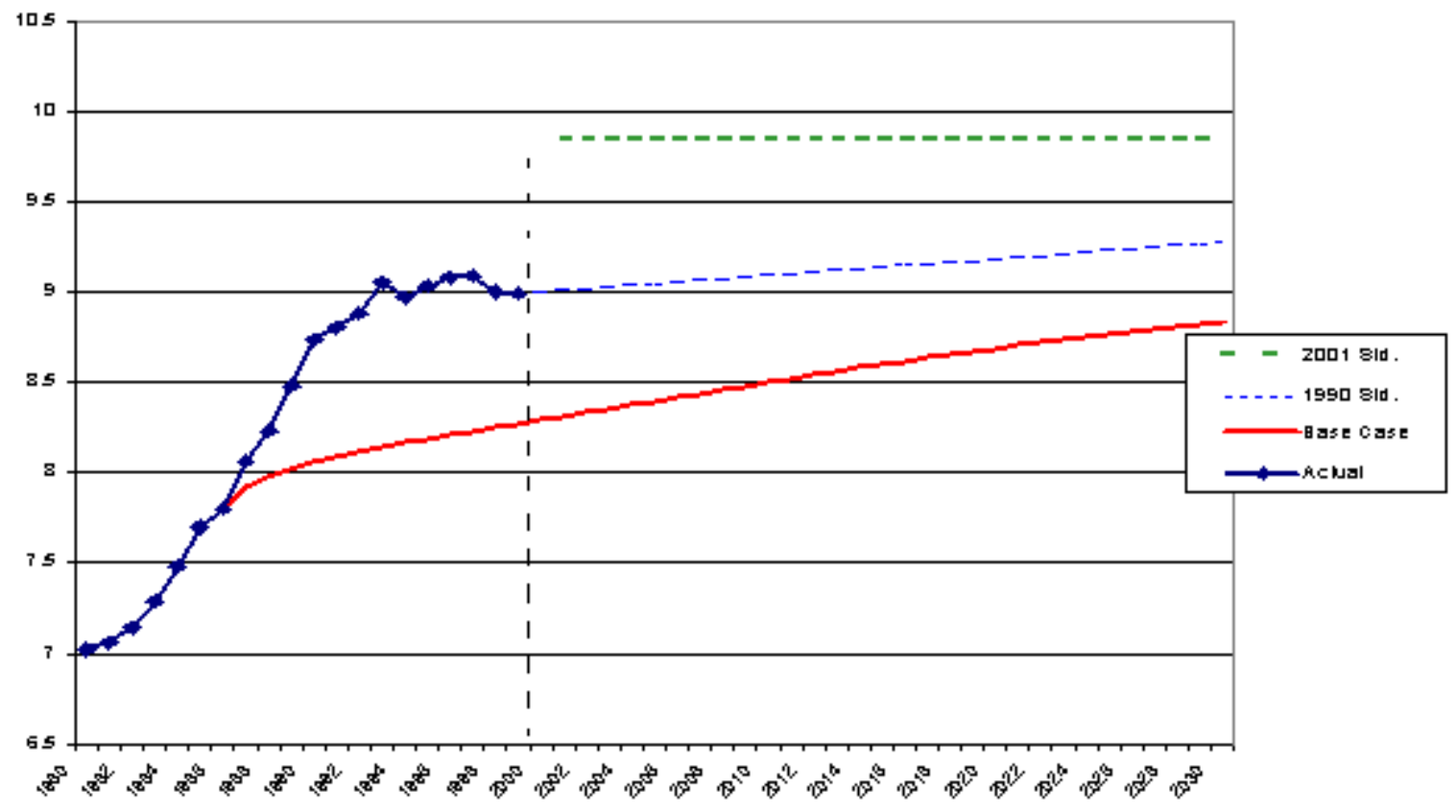

Figure 3.3 New Room Air Conditioners - Average EER, 1980-2030

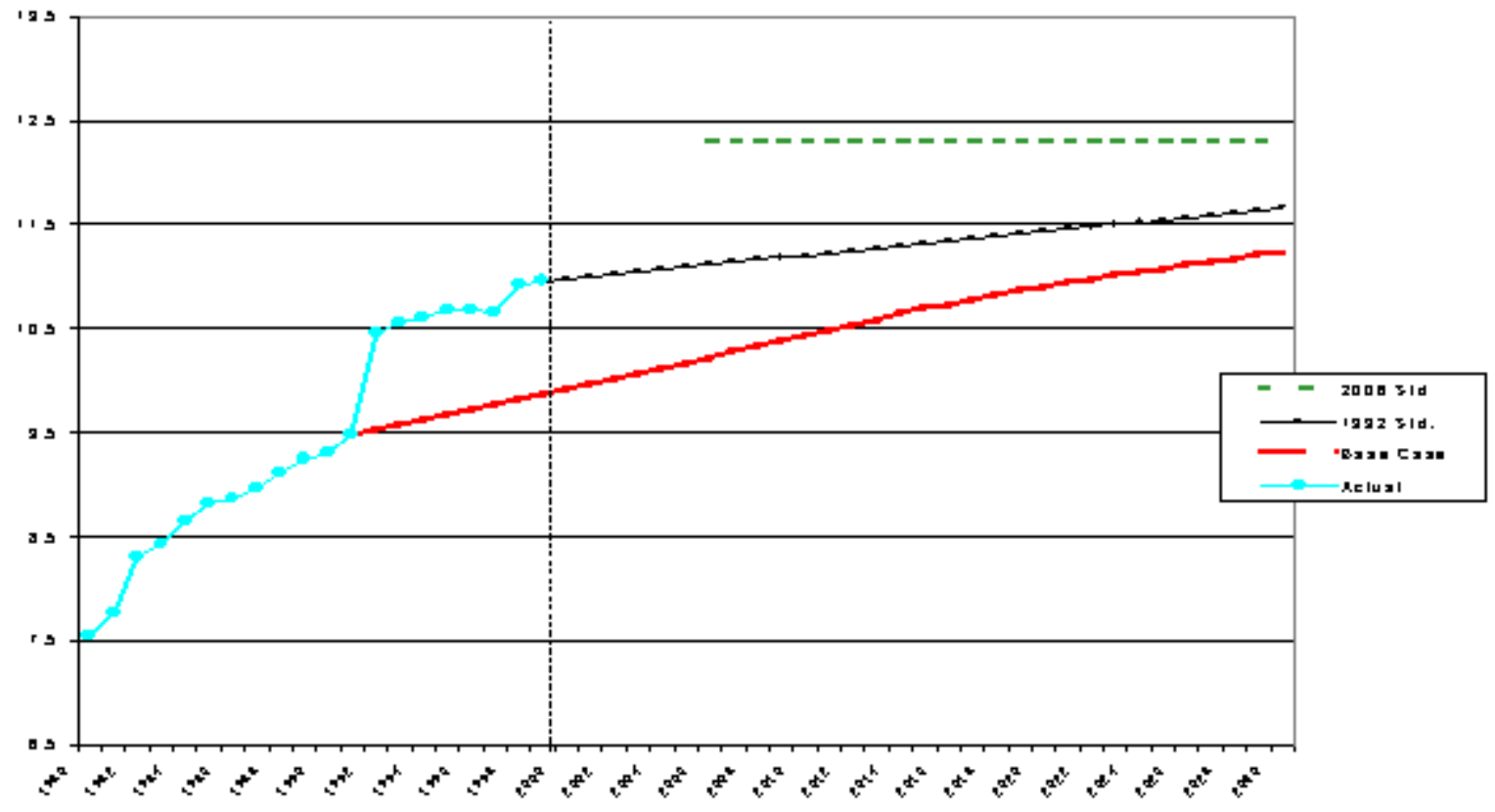

Figure 3.4 New Central Air Conditioners - Average SEER, 1980-2030 


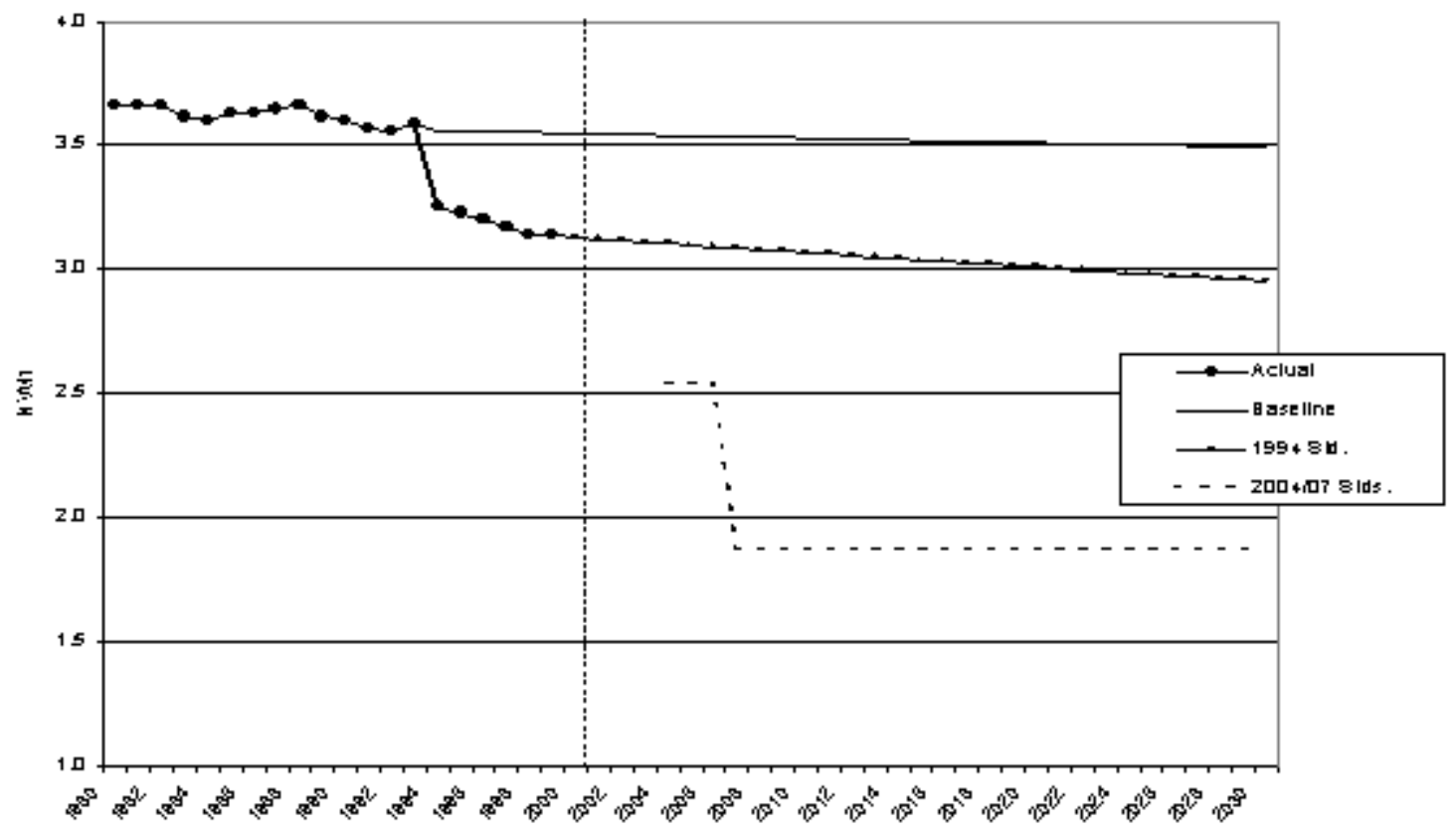

Figure 3.5 New Clothes Washers - Average Energy Use per Cycle (Washer, Dryer, and Water Heater Energy), 1980-2030

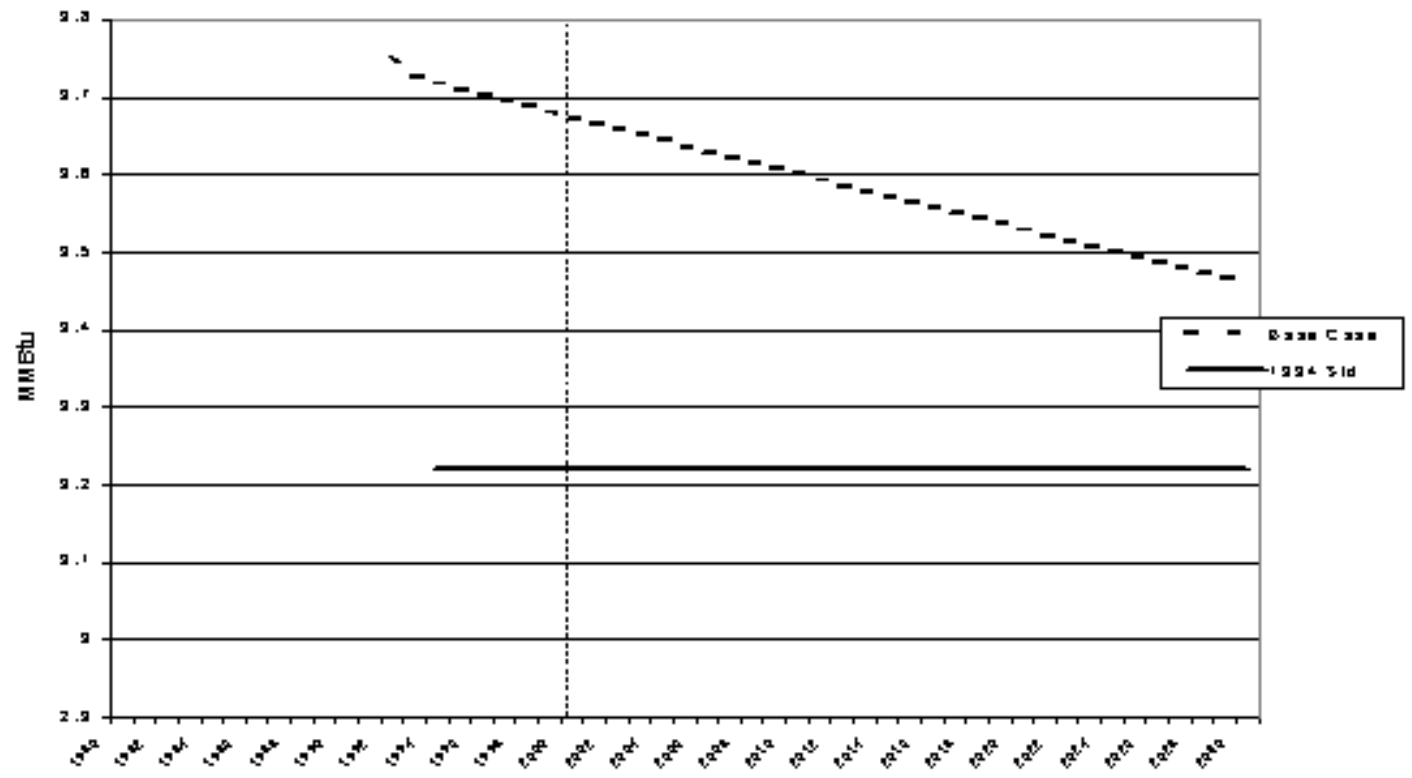

Figure 3.6 New Gas Clothes Dryers - Average Annual Energy Use, 1980-2030 


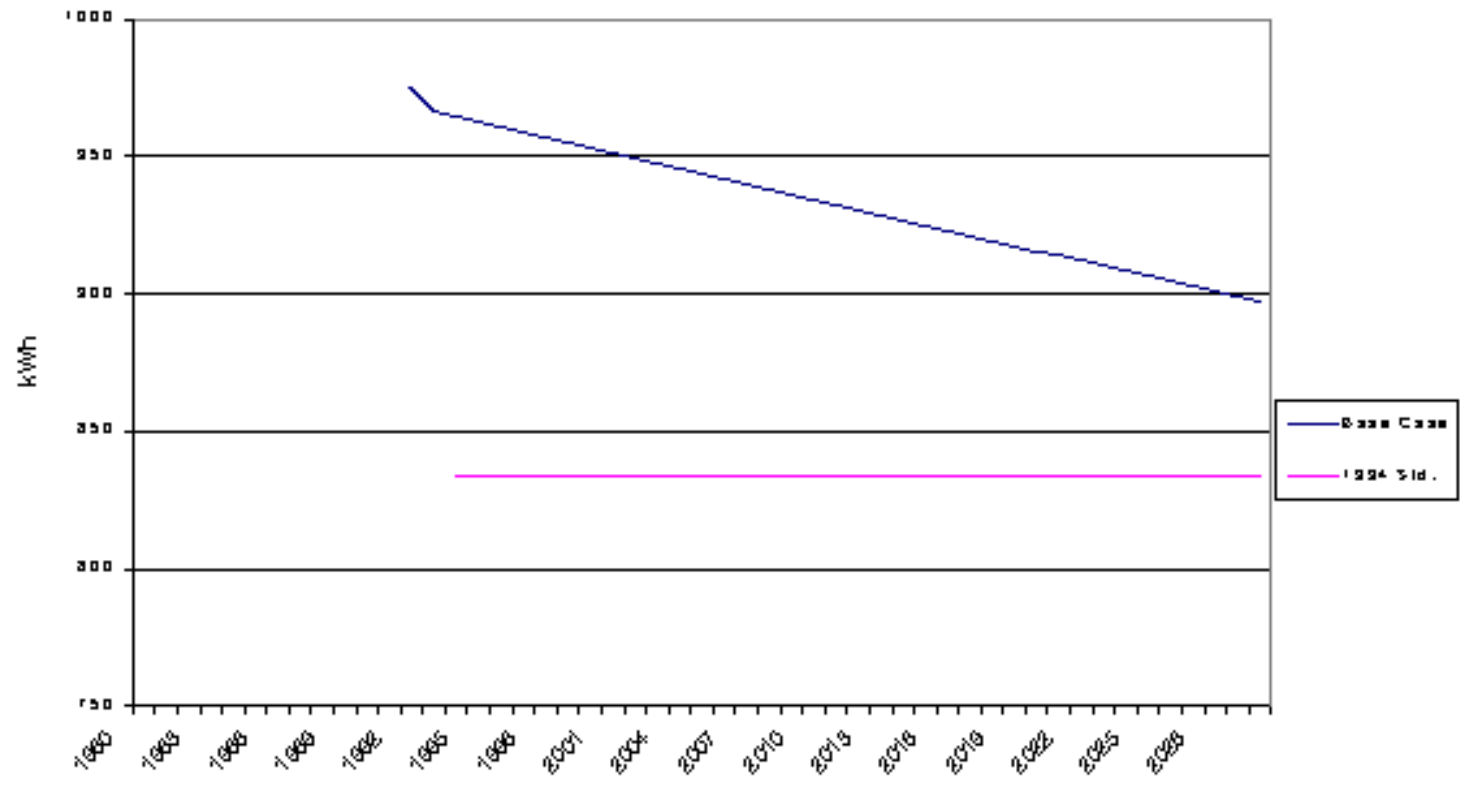

Figure 3.7 New Electric Clothes Dryers - Average Annual Electricity Use, 1980-2030

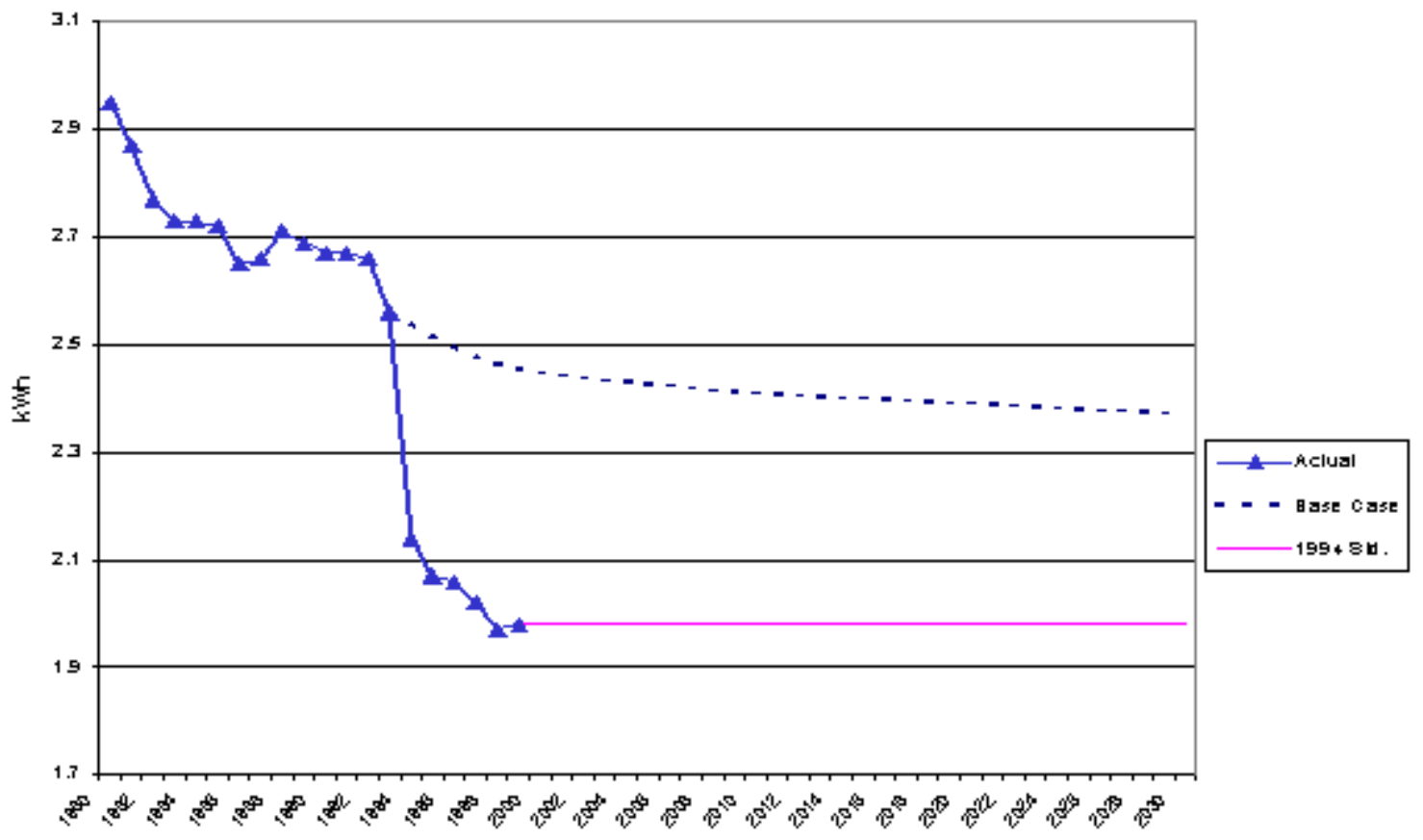

Figure 3.8 New Dishwashers - Average Energy Use per Cycle (Dishwasher and Water Heater Energy), 1980-2030 


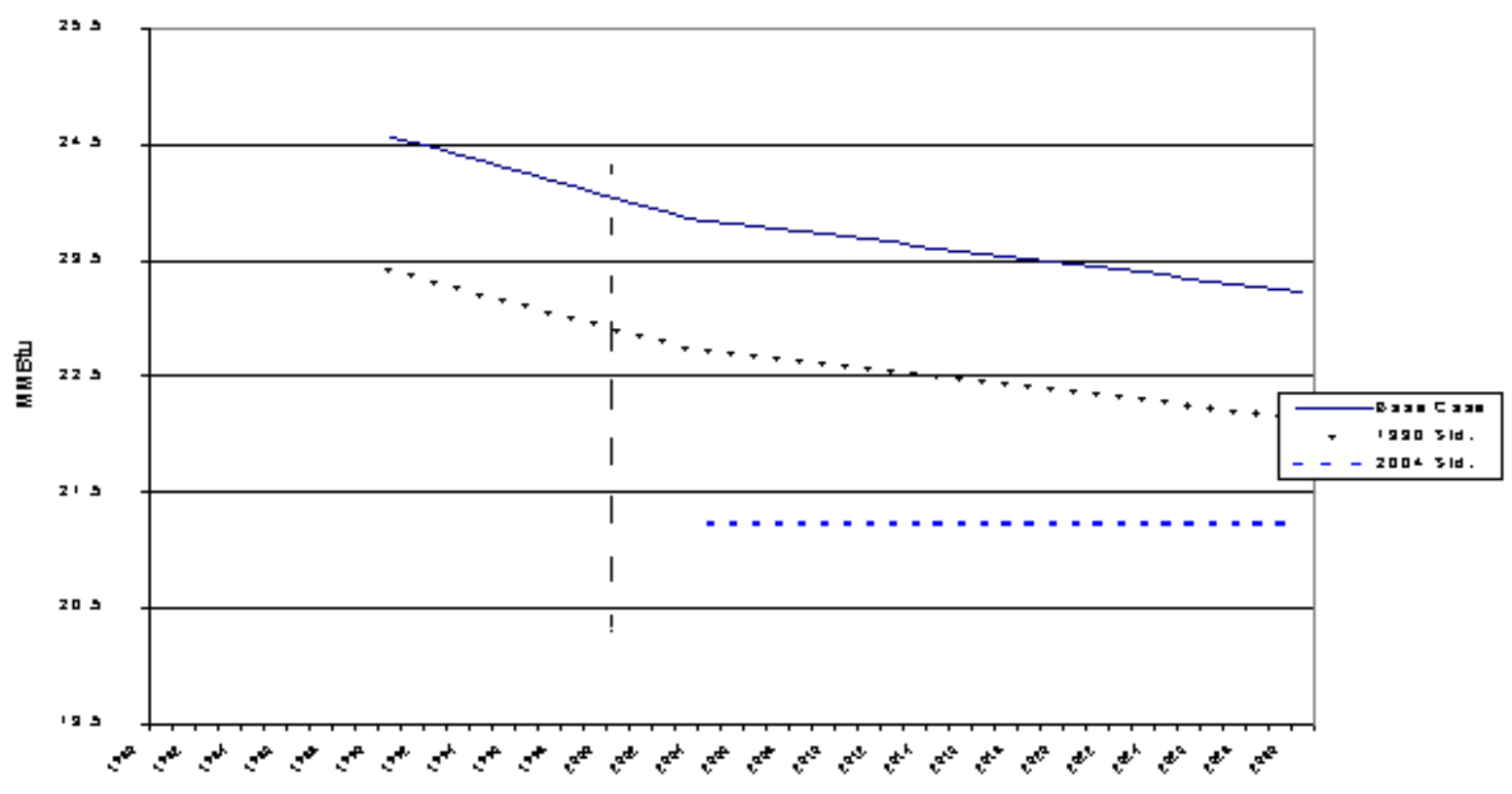

Figure 3.9 New Gas Water Heaters - Average Annual Energy Use, 1980-2030

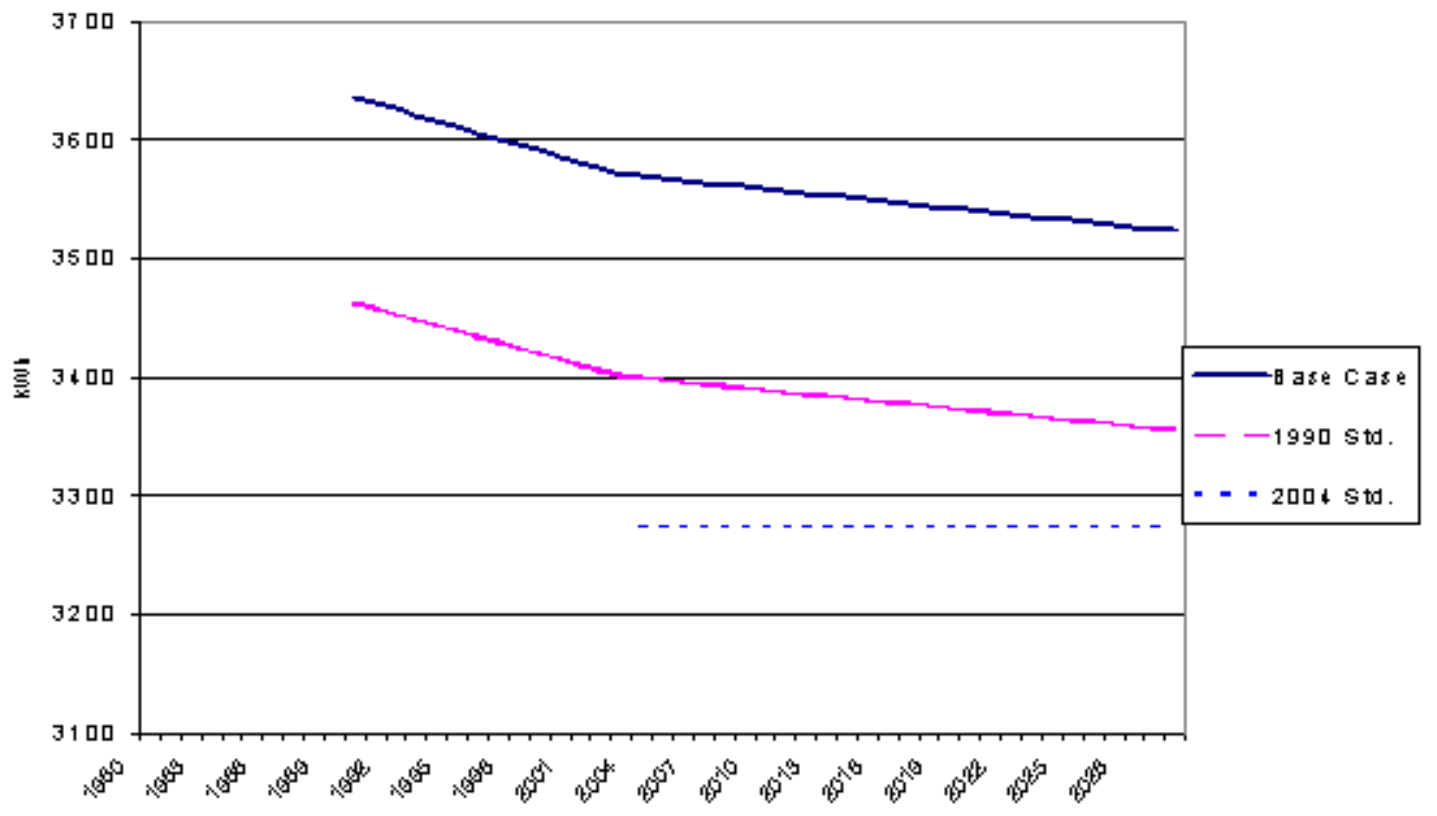

Figure 3.10 New Electric Water Heaters - Average Annual Energy Use, 1980-2030 


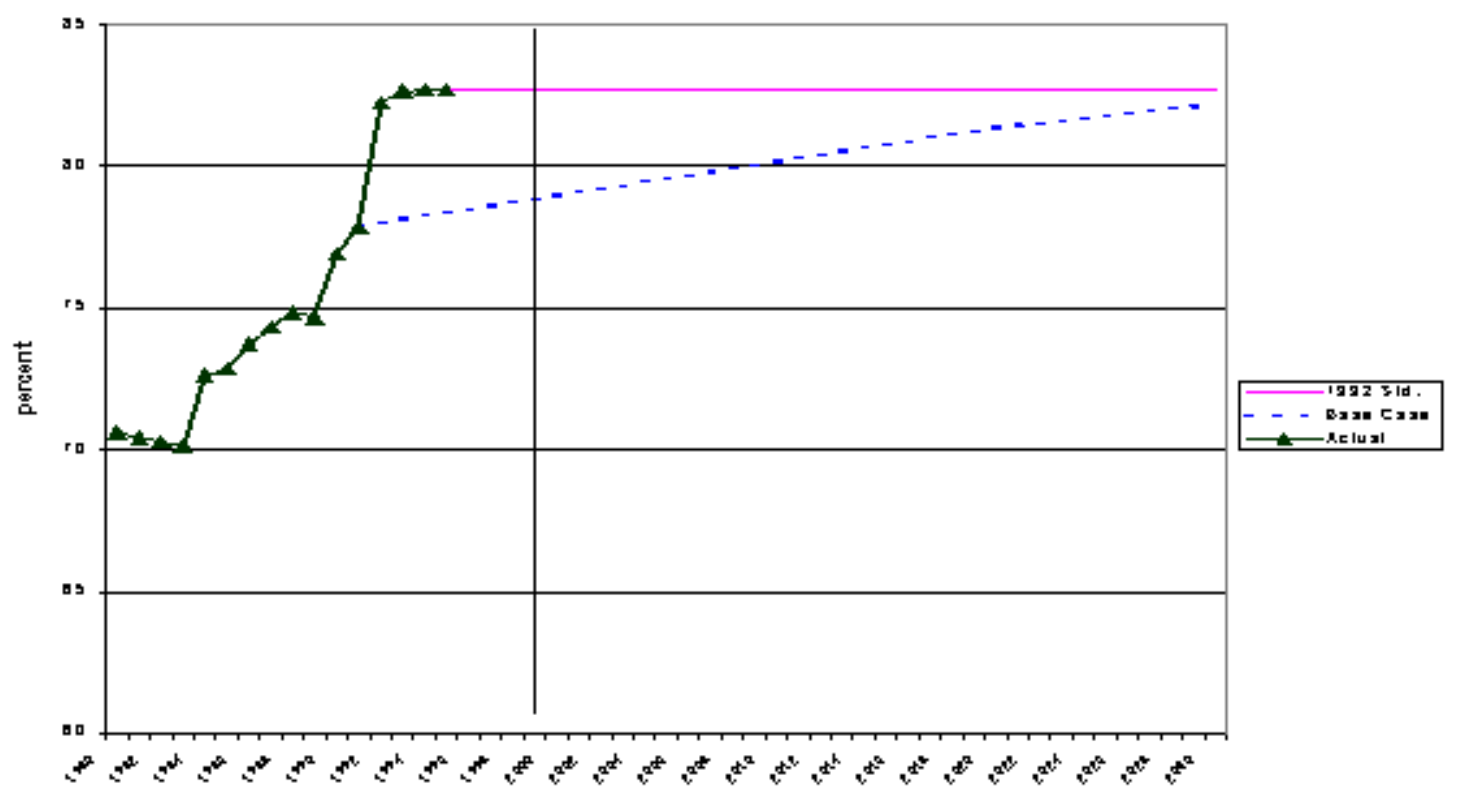

Figure 3.11 New Gas Furnaces - Average Fuel Utilization Efficiency, 1980-2030 


\section{Appliance Prices and Incremental Costs of Standards}

AHAM has published data based on market research on the average retail price of products sold in a given year for the following products:

- Refrigerators

- Freezers

- Room Air Conditioners

- Clothes Washers

- Clothes Dryers

- Dishwashers

We utilized these data to represent actual average prices in the 1985-1999 period.

The industry data show considerable decline in the average price (adjusted for inflation) between 1985 and the late 1990s for all of the above products (Figure 4-1). Looking at the trends, it is difficult to see an impact on price from DOE standards in most cases. However, we adopted the approach used in the TSDs and assumed that the standards did cause some additional cost. Effectively, we assume that prices would have been even lower in the absence of standards. Wherever incremental cost estimates were available from the TSDs, we applied the percentage incremental cost as estimated in the TSDs to the appropriate actual prices. Where such estimates were not available, we made estimates for this study. In our scenarios, average prices are correlated to average efficiency level. This relationship is determined from the prices of models of different efficiencies in a year for which such data are available.

For central air conditioners and heat pumps, we relied on cost estimates for different efficiency levels for 1998 new units made for the 2001 TSD. We applied these data to specific years in each scenario based on the estimated average SEER for each year, interpolating as needed (Figure 42). This method does not capture any cost trends independent of efficiency change that have occurred in the past. Thus, the estimated past values may not be accurate in absolute terms, but they should reasonably reflect the percentage change from one efficiency level to the next.

For water heaters, we utilized the average installed cost estimated for specific years in the 2001 TSD. As with central air conditioners, these estimates are based on the cost of models of different efficiency levels in a given year. The average cost in any given year is based on the average efficiency in that year.

For gas furnaces, we developed a time series for each scenario based on late-1990s prices for furnaces of a specific efficiency. We then used the average efficiencies in each year to derive an appropriate price. 
Although it is likely that the past trend of declining prices will continue to some extent, we have not attempted to estimate the shape of the future decline in average price in any of the scenarios. Rather, we focused on the relative difference in price between the base case and the standards cases, making sure that the price differential corresponds to the efficiency differential.

\section{References}

Association of Home Appliance Manufacturers, 1999 (1997, 95, 93 87). Major Appliance Industry Fact Book. Chicago, IL.

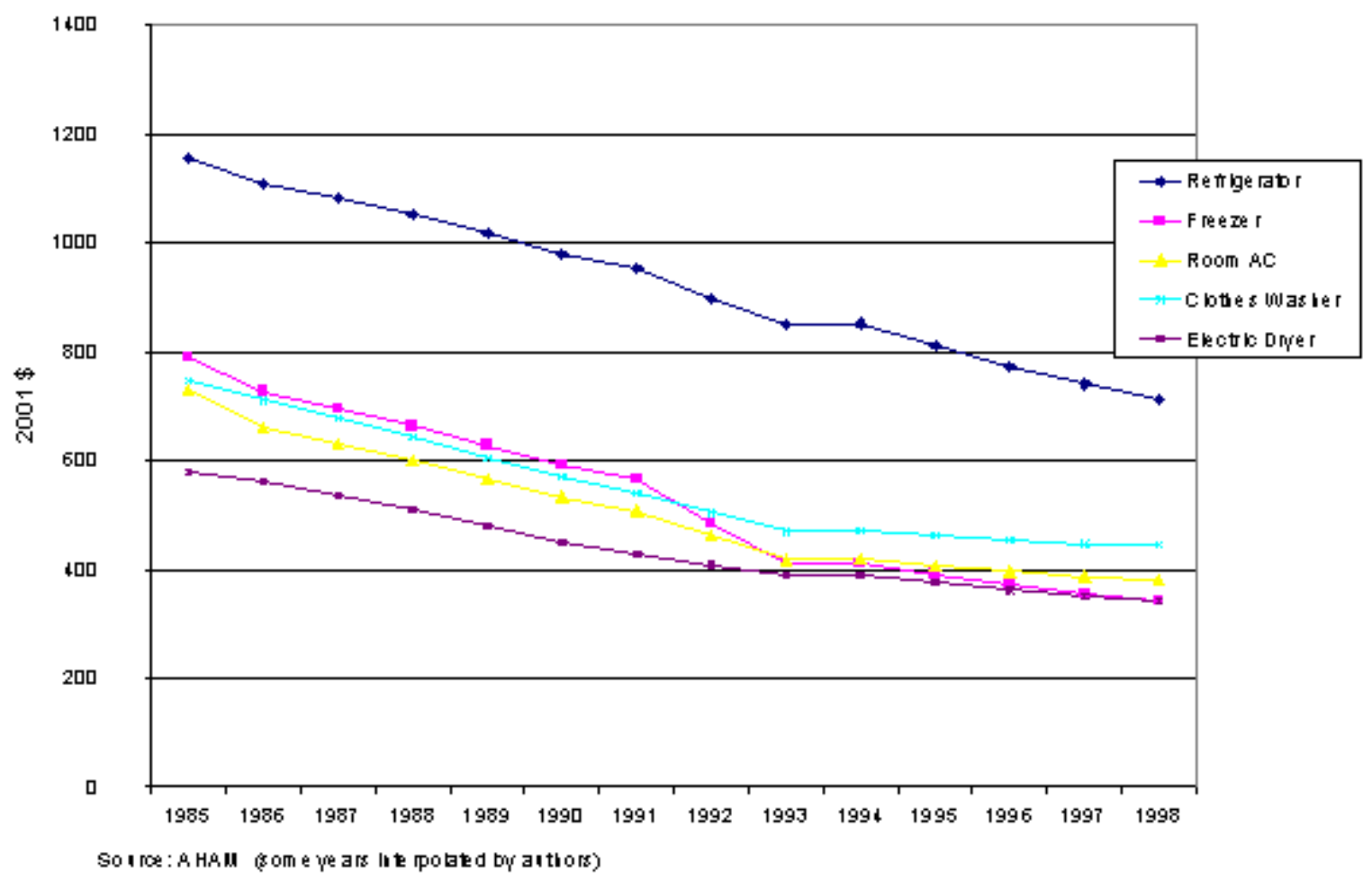

Figure 4.1 Average Retail Price of Selected Appliances, 1985-1999 


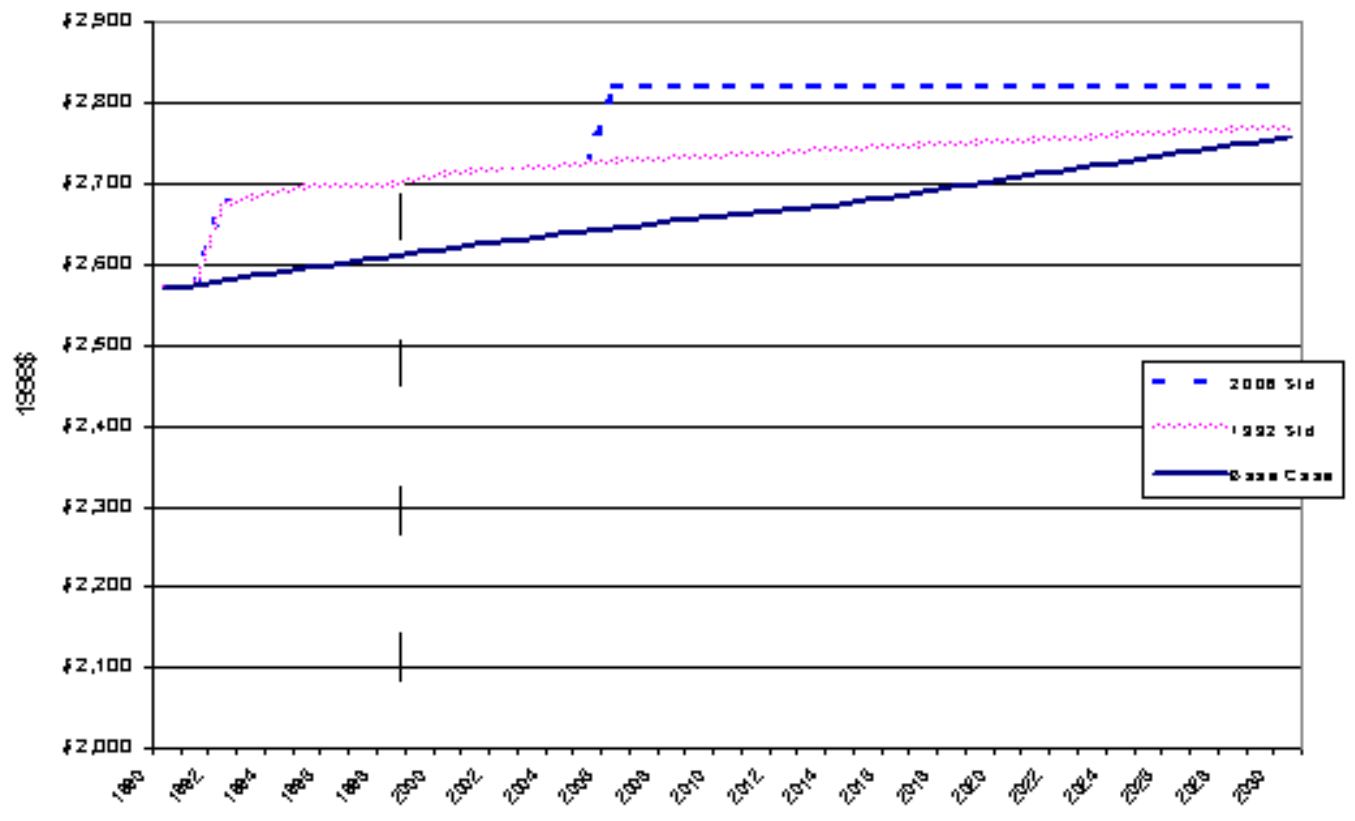

Figure 4.2 New Central AC \& Heat Pumps - Average Installed Cost (Estimated Based on SEER), 1990-2030 


\section{Energy Savings Due to Standards}

This section presents estimates of the national energy savings for the original NAECA standard for each product and for each update, as well as total savings from standards. The method of the calculations is described below. The general approach is to consider each update as building on top of the previous standard level. Thus, the original NAECA standards continue to have some impact for new shipments throughout the considered period, since the difference between the "no standards at all" baseline and the NAECA standard scenario is always attributed to the NAECA standard, even when its minimum efficiency levels have been superceded by a new update. In turn, the savings attributed to the update are relative to the NAECA standard scenario. In all scenarios, the savings end when the last of the products purchased in 2030 leaves the stock.

\section{End-Use Energy Savings per New Unit}

For products sold in 1987-1999, we used the "actual" data presented in Section 3 to estimate the energy savings due to standards. For each standards scenario, we calculated end-use energy savings per unit for each year as the difference between the actual AAEU or energy efficiency and the value in the particular scenario (see, for example, the left-hand side of Figure 3.1).

In all cases, the actual average energy efficiency exceeded the minimum required by the standard, sometimes by a significant amount. Such an outcome is to be expected. Since some models already were above the minimum required when the standard removed the least efficient models, from the market the resulting average was greater than the standard level. For gas furnaces, for example, the 1992 standard set a minimum AFUE of 78\%, but the average AFUE of furnaces sold in 1992 was $83 \%$. The reason is that roughly $20 \%$ of sales were of highly efficient (90-92\%) condensing furnaces, while the remainder were at or better than the $78 \%$ minimum. The increasing share of condensing furnaces was occurring without the NAECA standard, but the standard increased the average efficiency of the other furnaces in the market.

Where actual data are lacking (water heaters and clothes dryers), we used the difference between the standard scenario and the base case to derive energy savings.

For products sold in 2000-2030, we calculated the end-use energy savings per unit for each year as the difference between the AAEU or energy efficiency in each standard scenario relative to the previous scenario.

\section{National End-Use Energy Savings}

The calculations use a product retirement function to calculate the number of units in a given vintage that are still in operation in each year. The retirement function assumes that individual appliance lifetime is normally distributed around a mean lifetime. The width of the distribution 
is such that almost all units retire within a few years of the average lifetime. The mean lifetime for the appliances is as follows:

\begin{tabular}{|l|c|}
\hline \multicolumn{1}{|c|}{ Appliance } & Mean Lifetime (years) \\
\hline Refrigerators & 19 \\
\hline Freezers & 19 \\
\hline Central Air Conditioners & 12.5 \\
\hline Room Air Conditioners & 12.5 \\
\hline Clothes Washers & 14 \\
\hline Dishwashers & 12.6 \\
\hline Water Heaters (Electric/Gas) & $11 / 9$ \\
\hline Gas Furnaces & 17 \\
\hline
\end{tabular}

Source: Technical Support Documents (see Appendix 1)

The model calculates the energy savings for each standard or update as the difference in national energy consumption between the appropriate scenarios. It tracks energy savings into the future until all of the units installed in 2030 are retired.

\section{National Primary Energy Savings}

We calculated the primary energy required for production and delivery of end-use electricity and natural gas in each year using data for the residential sector in EIA's Annual Energy Review and Annual Energy Outlook. These data yield an average primary-to-end use energy multiplier for each year.

Figures 5-1 through 5-10 depict the annual primary energy savings for each standard, as well as the total savings for the product. Each line in Figures 5-1 through 5-10 refers to the estimated savings attributable to each standard or update. For refrigerators, for example, the savings from the 2001 update are in addition to those estimated for the 1990 standard and the 1993 update. The total savings are the sum of the savings of each standard and update.

Figure 5-11 shows the annual primary energy savings for all products together. The fall in savings after 2030 occurs because that is the last year for which we count product shipments. After 2030, as the products purchased in earlier years age, we continue to count savings until all products purchased in 2030 retire.

The total primary energy savings from DOE residential standards in 2020 are 2.3 quads. EIA's Annual Energy Outlook 2002 has a projection for total residential primary energy consumption of 
24 quads in the reference case. As this projection includes the effect of appliance standards, the consumption without the standards would be approximately 26 quads. Thus, we estimate that the standards will reduce residential energy consumption in 2020 by $8 \%$.

The estimated absolute growth in residential primary energy consumption between 1990 and 2020 without standards is 10 quads. The standards reduce this growth to 8 quads.

Figure 5-12 presents the cumulative primary energy savings from 1987 through 2050 for each product. Refrigerators and clothes washers claim the greatest savings.

Figure 5-13 presents the cumulative primary energy savings for all products together in selected years. The cumulative savings are just over 60 quads in 2030, and approach 80 quads by 2050 . 


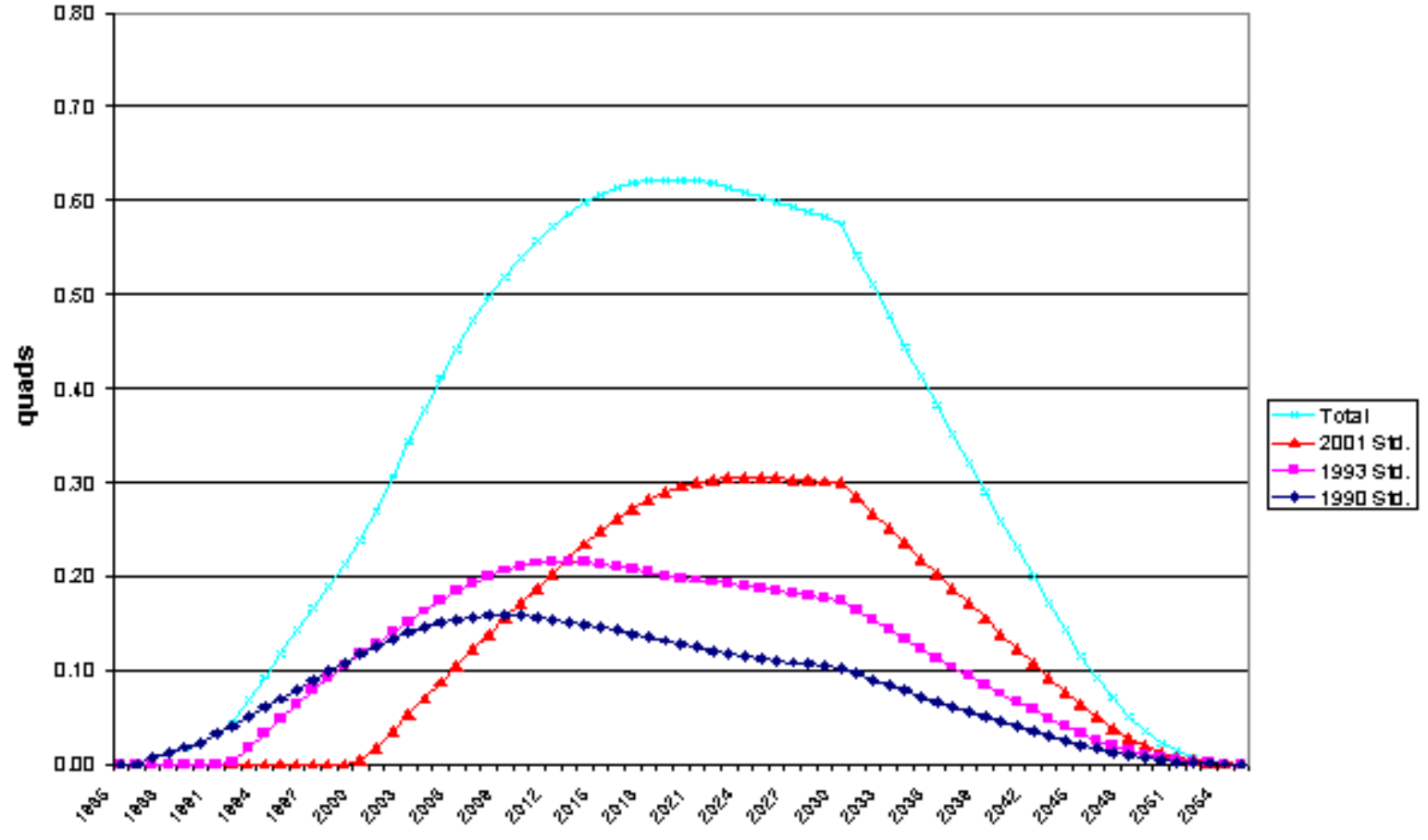

Figure 5.1 Refrigerator Standards - Annual Primary Energy Savings, 1985-2055

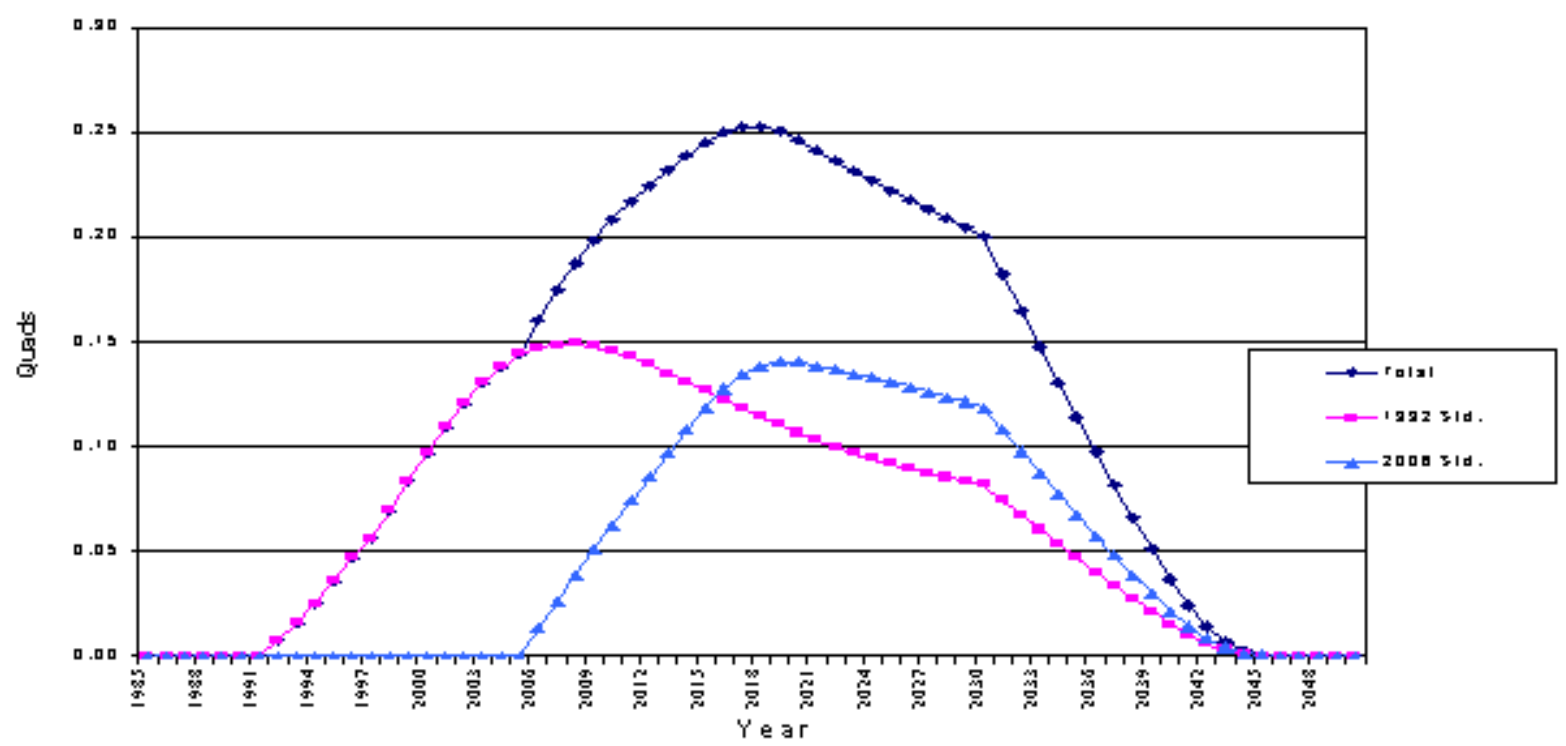

Figure 5.2 Freezer Standards - Annual Primary Energy Savings, 1985-2050 


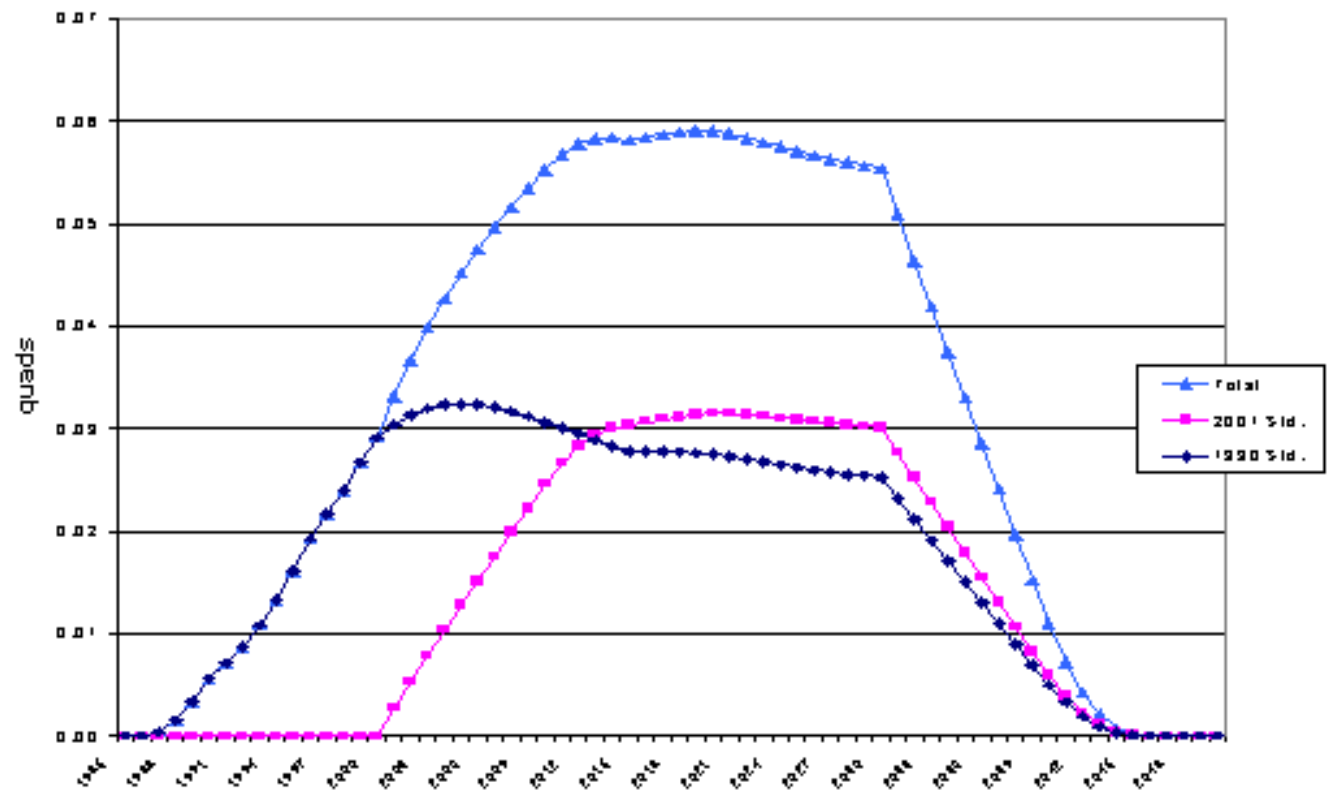

Figure 5.3 Room Air Conditioner Standards - Annual Primary Energy Savings, 19852050

New Freezer Standards Annual Primary Energy $S$ avings 1985-2050

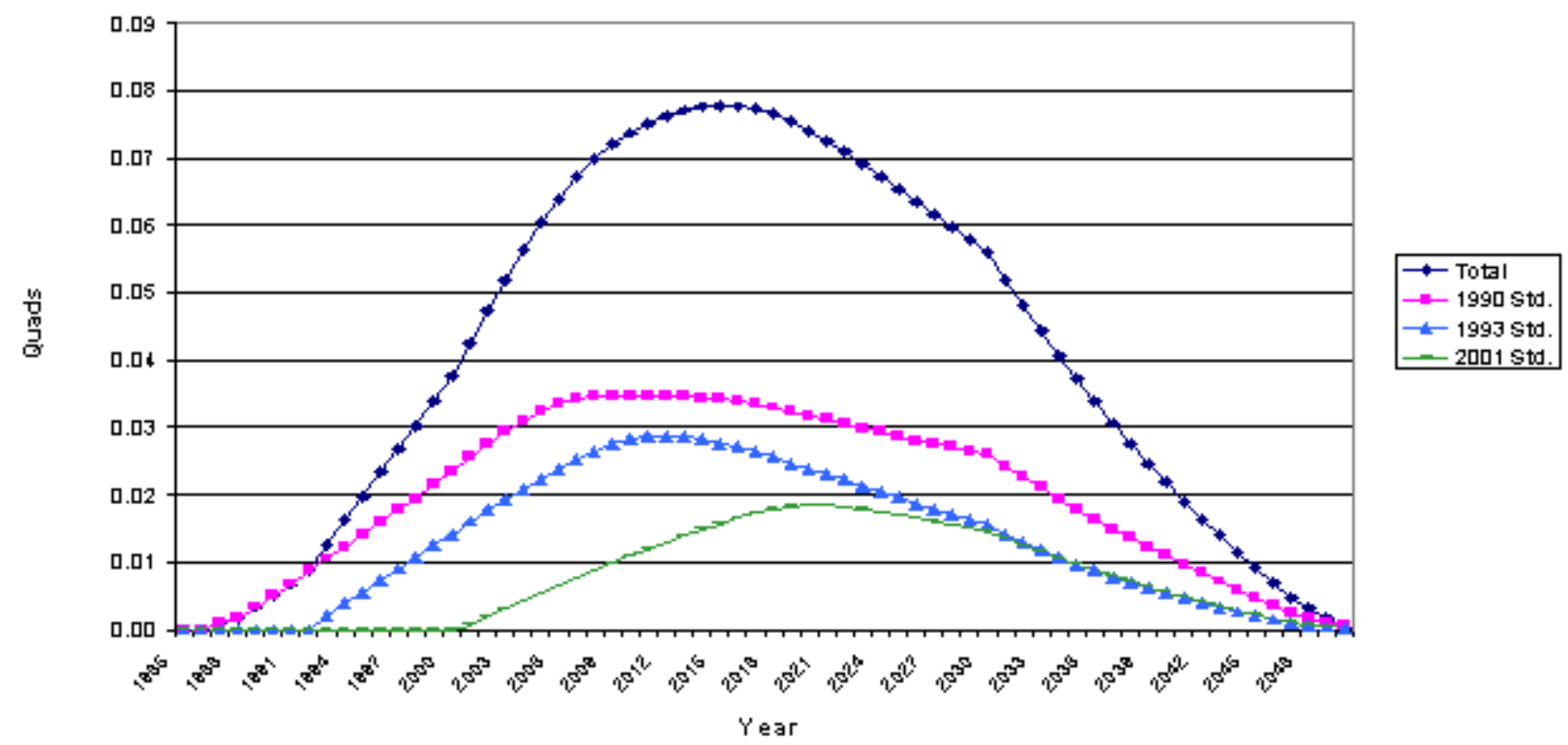

Figure 5.4 Central Air Conditioner Standards - Annual Primary Energy Savings, 19852050 


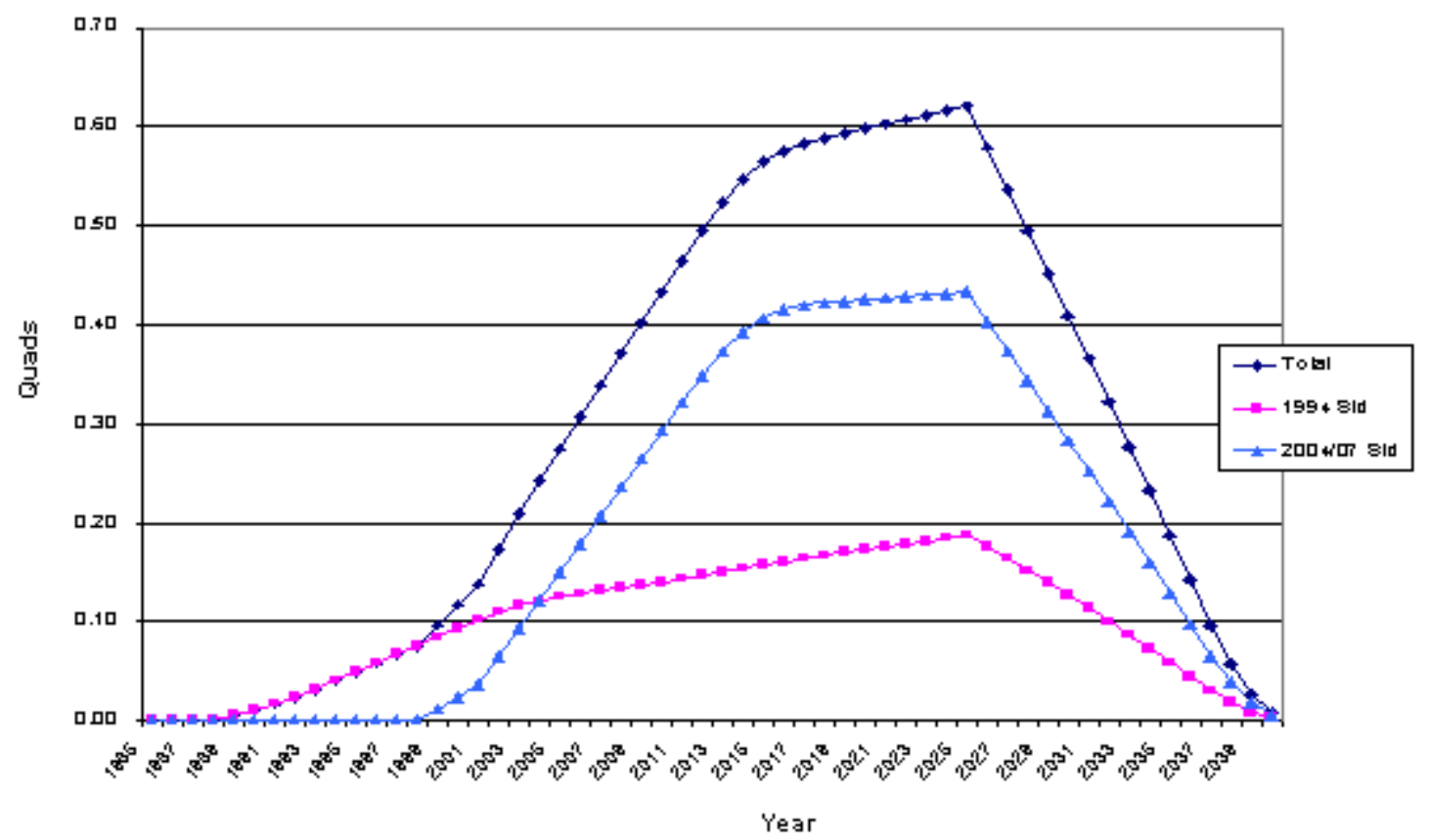

Figure 5.5 Clothes Washer Standards - Annual Primary Energy Savings, 185-2050

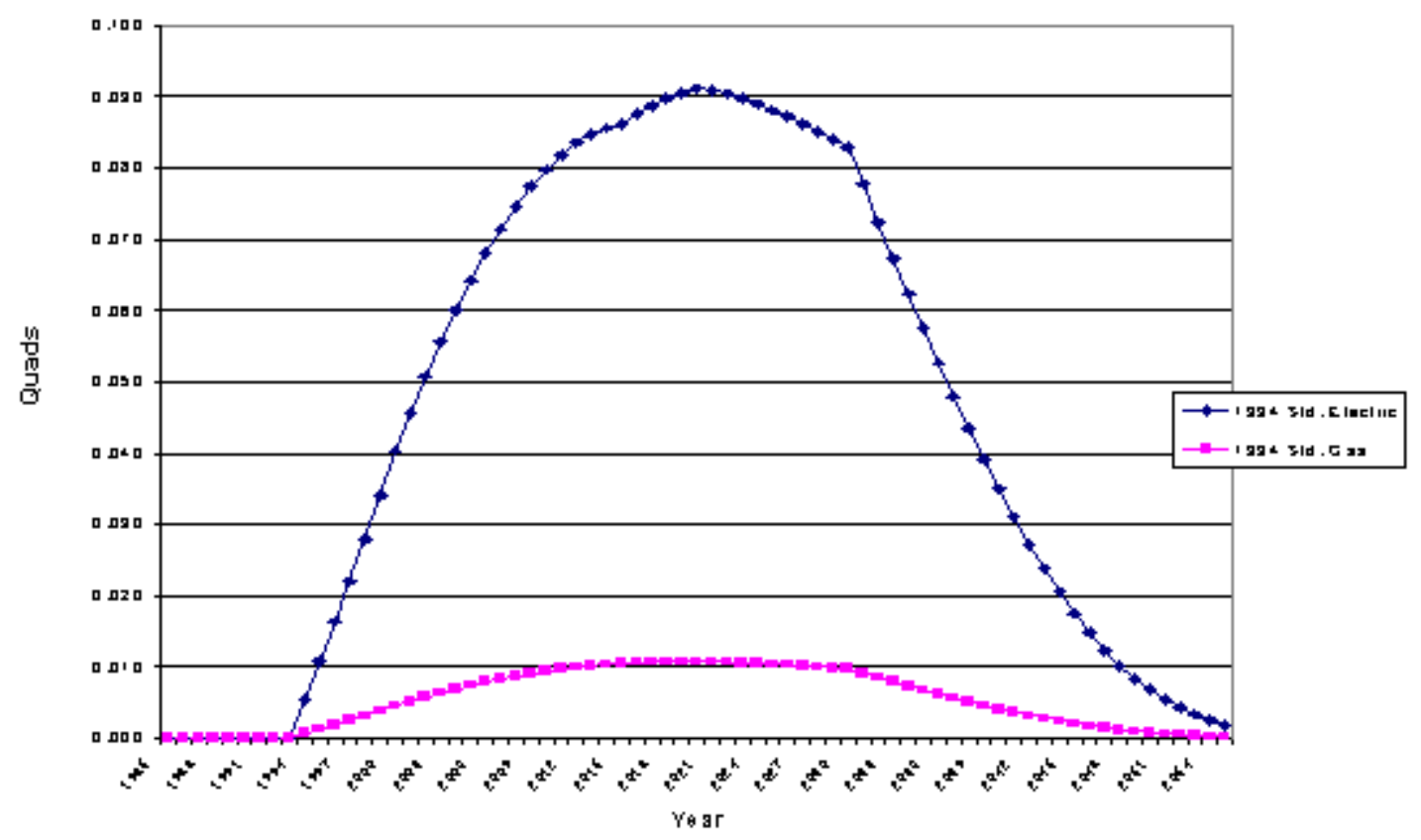

Figure 5.6 Clothes Dryer Standards - Annual Primary Energy Savings, 1985-2055 


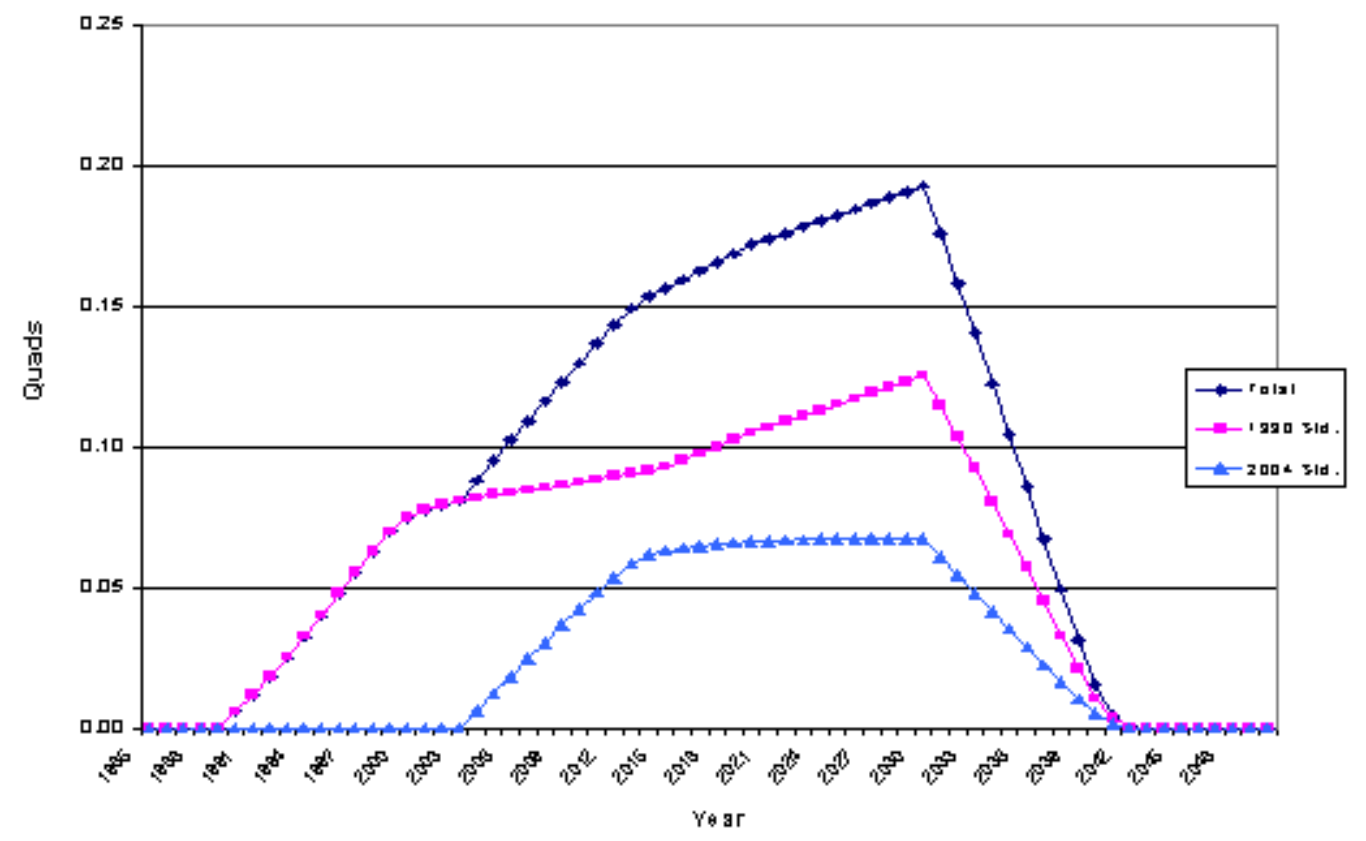

Figure 5.7 Dishwasher Standards - Annual Primary Energy Savings, 1985-2050

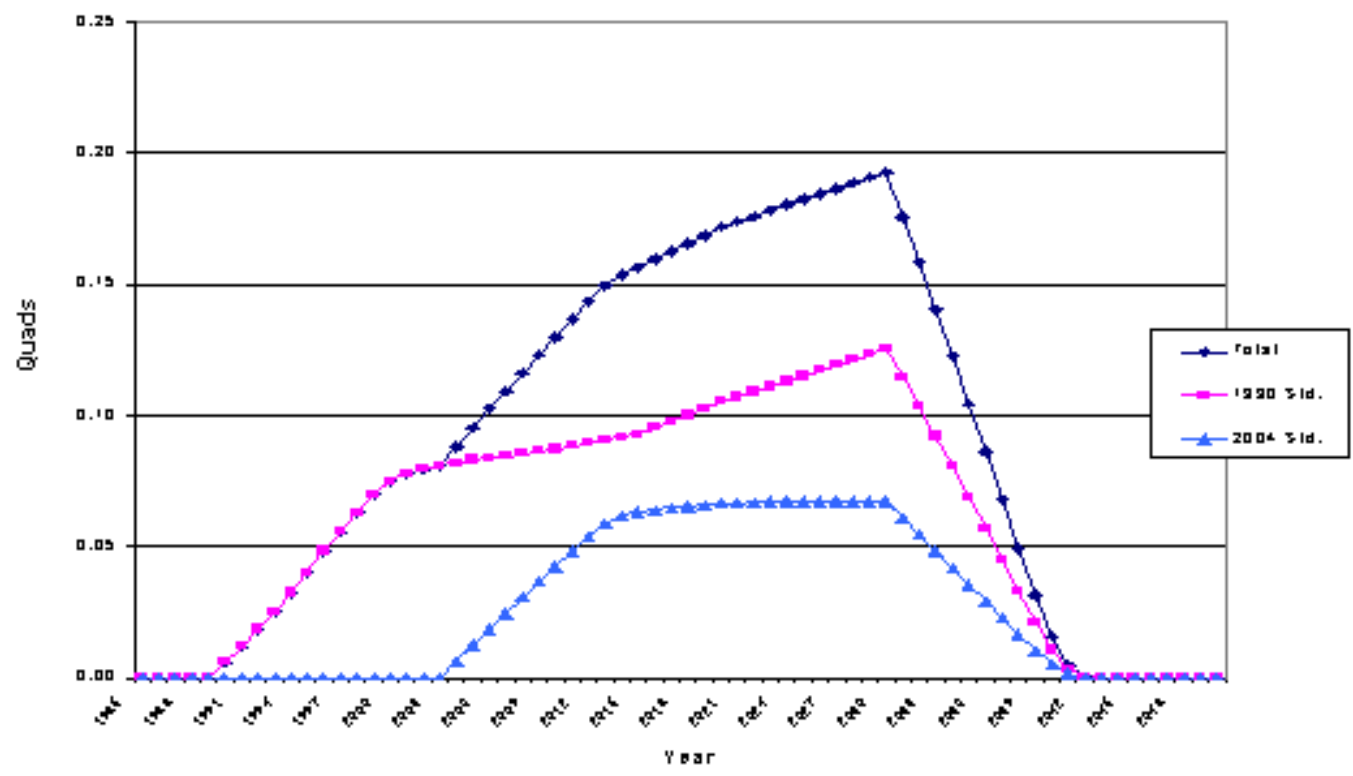

Figure 5.8 Electric Water Heater Standards - Annual Primary Energy Savings, 19852050 


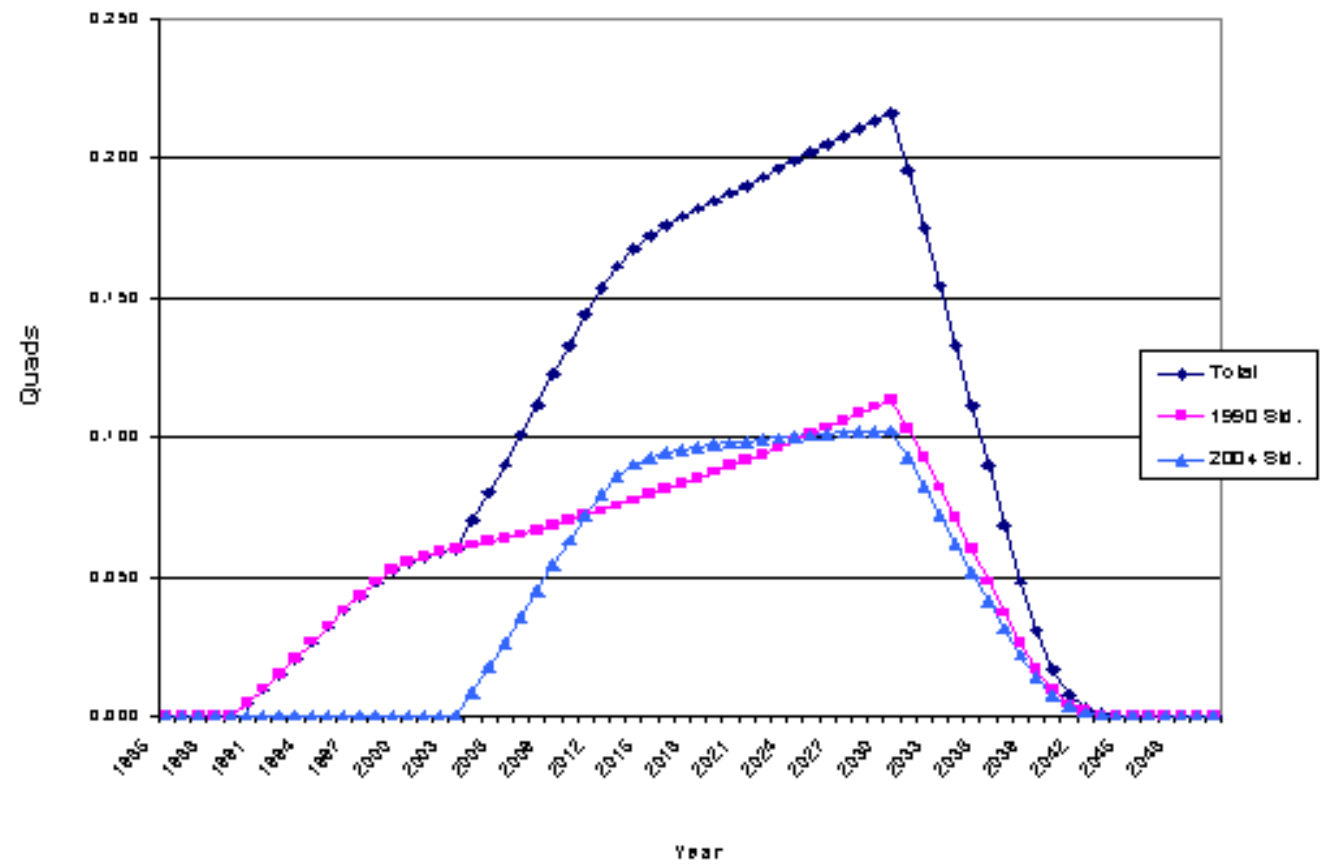

Figure 5.9 Gas Water Heater Standards - Annual Primary Energy Savings, 1985-2050

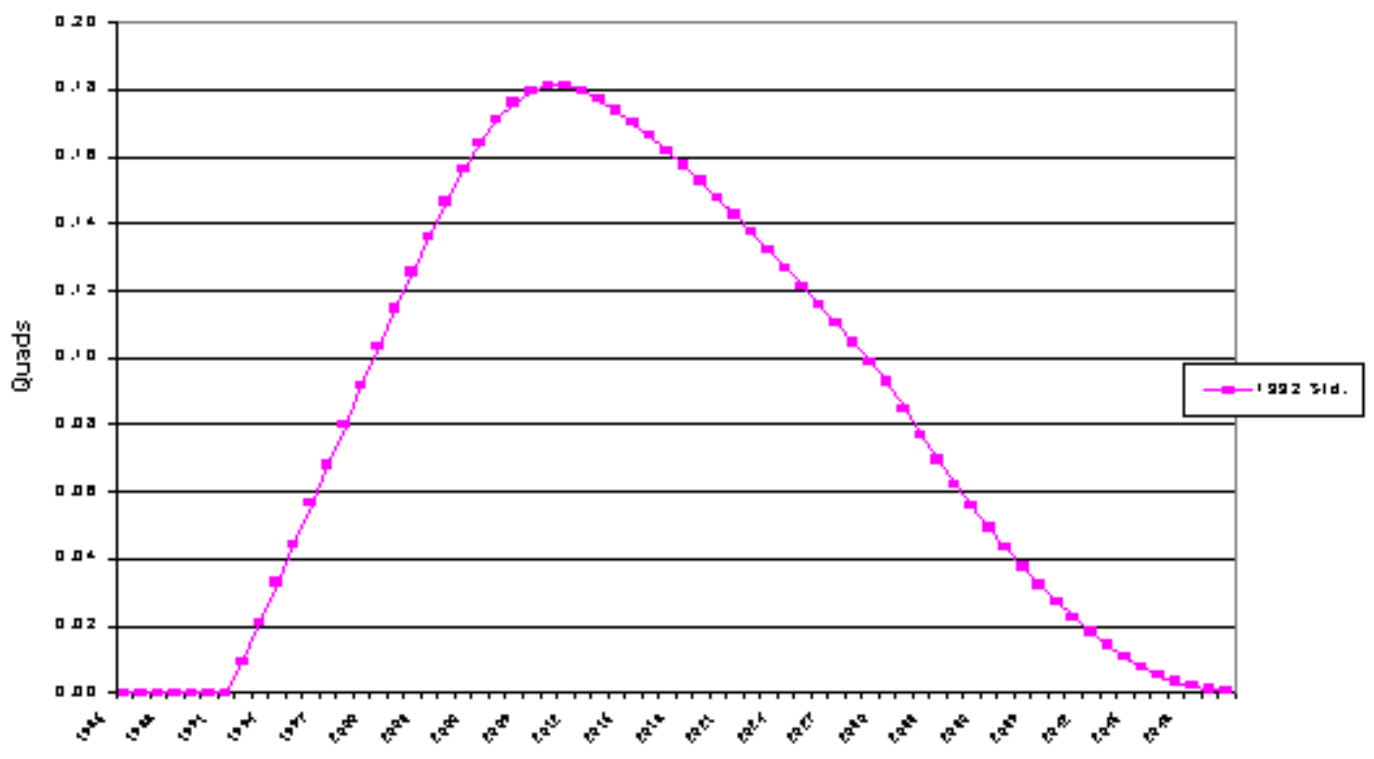

Figure 5.10 Gas Furnace Standards - Annual Primary Energy Savings, 1985-2050 


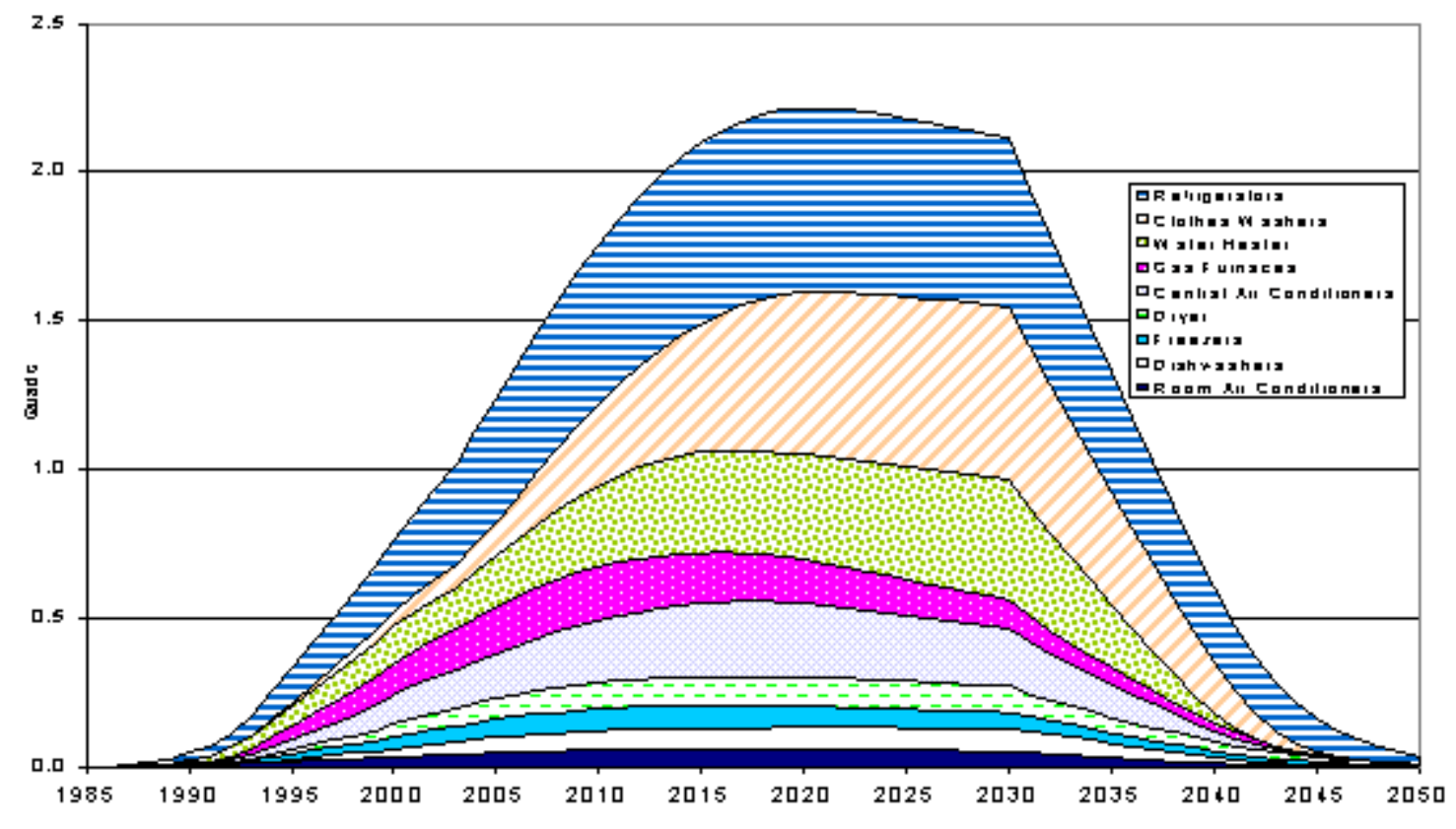

Figure 5.11 Annual Primary Energy Savings from DOE Appliance Standards by Product

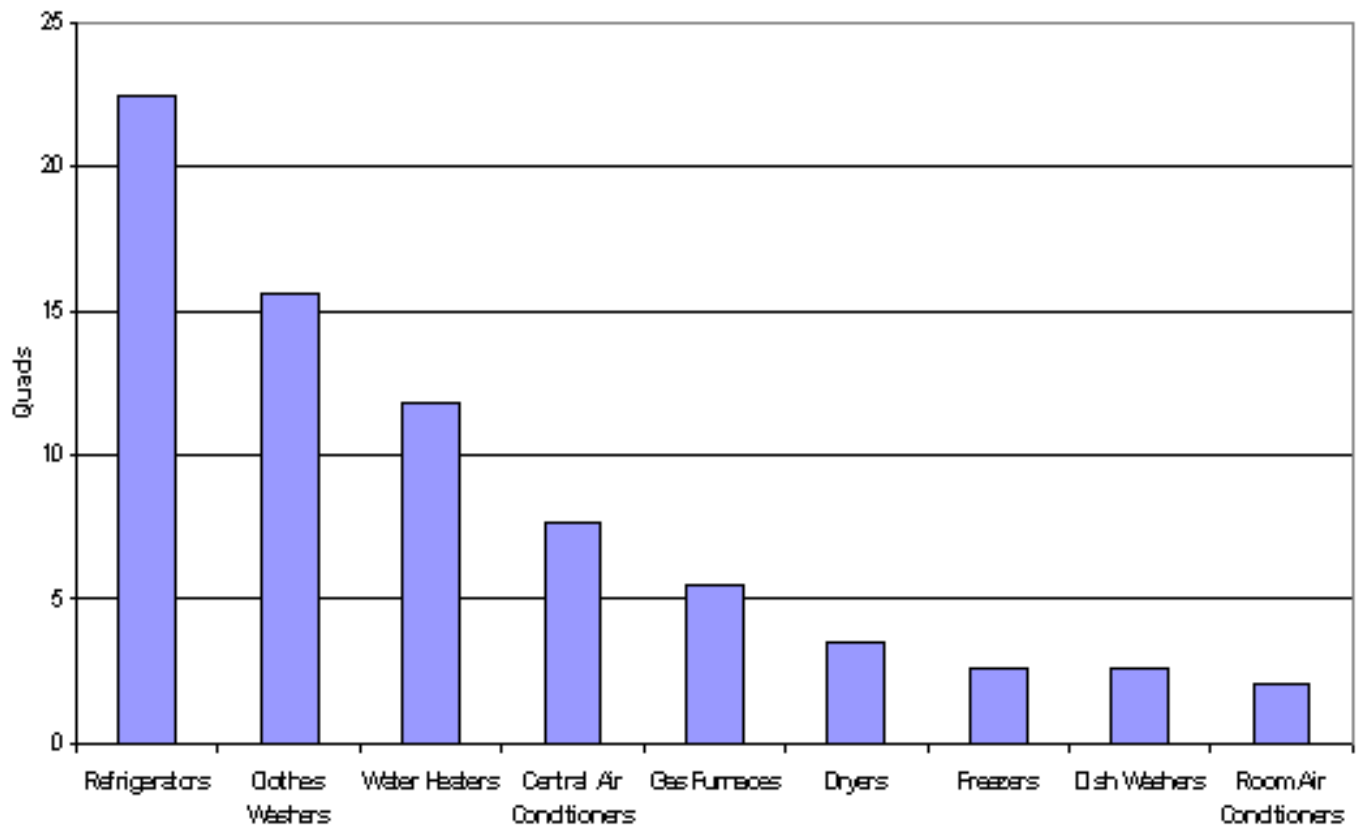

Figure 5.12 Cumulative Primary Energy Savings from DOE Appliance Standards by Product, 1987-2050 


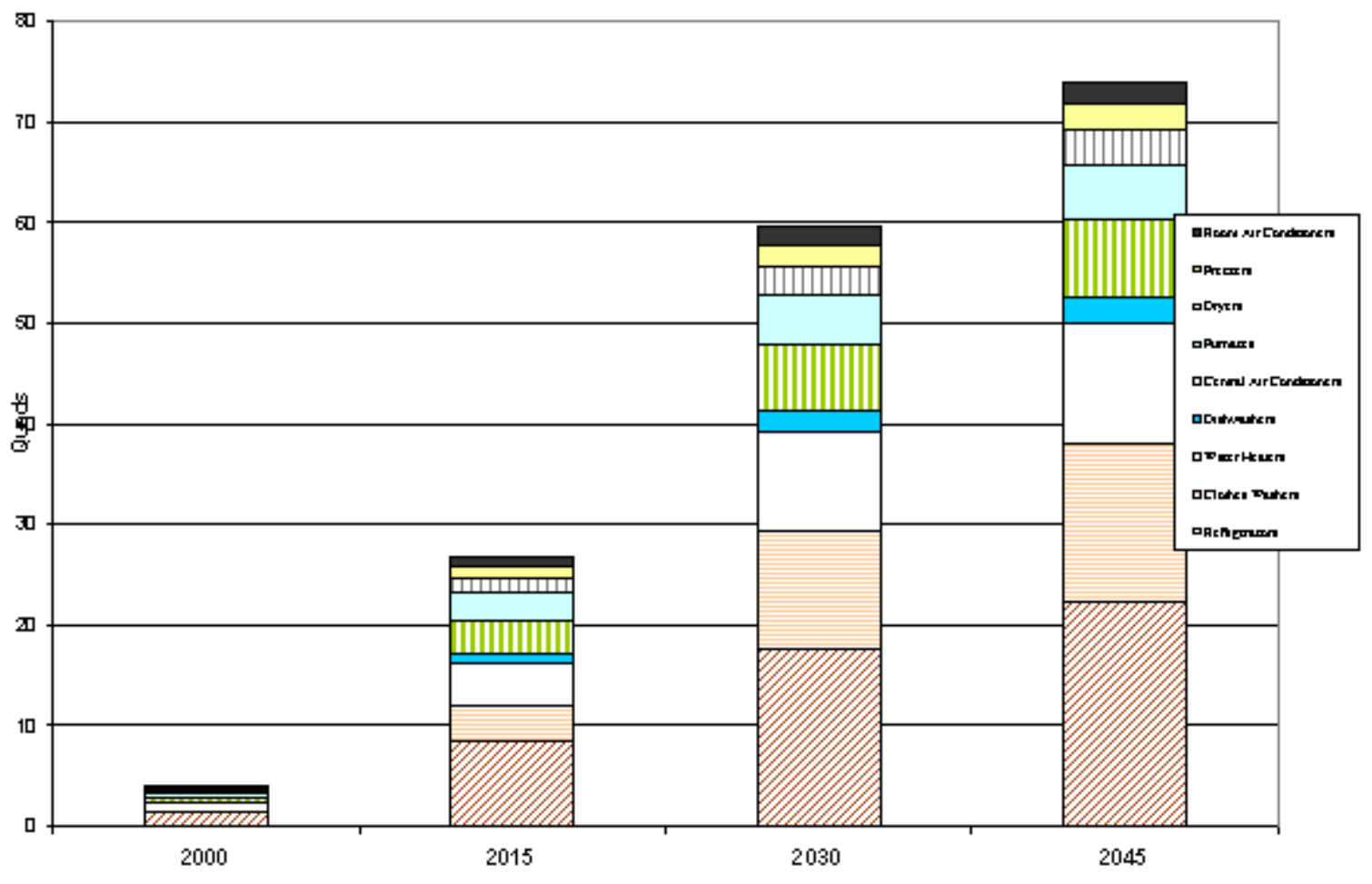

Figure 5.13 Cumulative Primary Energy Savings between 1987 and Specific Years from DOE Appliance Standards 


\section{National Consumer Costs and Benefits Due to Appliance Standards}

Figure 6-1 shows the annual operating cost benefits, additional product cost, and net benefits for all of the standards together. The operating cost savings are electricity and natural gas savings valued at the national average residential retail price for each year. The additional product cost is the estimated incremental purchase price. For products that reduce water consumption (clothes washers and dishwashers), we include savings on water expenditures in the operating cost benefits. For clothes washers, such savings are a significant fraction of the overall savings. All values are expressed in year 2001 dollars.

We express the benefit of appliance standards to consumers in terms of the Net Present Value (NPV) of costs and benefits over the expected lifetime of products. To express NPV, we discount future costs and savings in each year to the present (end-2001) using a rate of 7\% (real), which is the rate used by DOE in its analyses of appliance standards. To express the present value of net savings achieved in the 1987-2000 period, we apply an annual interest rate of 3\% (the approximate average return on long-term government bonds) to the net savings in each year, allowing interest to accumulate through 2001..$^{5}$ The resulting NPV of cumulative benefits from the standards for each product is shown in Figure 6-2. The bulk of the net savings are associated with standards for three products: refrigerators, clothes washers, and water heaters.

Figure 6-3 gives the cumulative net benefits for all products together for various periods. As of end-2000, the standards had saved U.S. consumers an estimated $\$ 17$ billion. The present value of projected net savings over the entire $1987-2050$ period is approximately $\$ 150$ billion. The ratio of consumer cost savings ( $\$ 241$ billion) to additional consumer expenditures ( $\$ 88$ billion) is 2.75:1. The amount of taxpayer funds used to support DOE's residential appliance standards program over the past 20 years is in the range of \$200-250 million. Thus, the leveraging effect of the government expenditure on consumer benefit is quite large.

We believe that the actual consumer benefits achieved to date, as well as the prospective benefits, are understated in this study. We have relied on engineering estimates to calculate the incremental cost of products that meet efficiency standards. However, both statistical analysis and anecdotal evidence indicate that the actual extra cost faced by consumers has been less than

\footnotetext{
${ }^{5}$ Interest rates represent the marginal value of savings to society, determining what next years money is worth today and what today's money will be worth next year. Economists take advantage of this definition and use interest rates to convert future savings into a present value (in which case the interest rate is called a discount rate) and to convert past savings into a present value. Over time, all savings are subject to risk and interest rates change in proportion to the level of that risk. For example, low risk long term government bonds yielded roughly $3 \%$ in past decades while equity stocks, which face higher risk, yielded over $7 \%$. Consistent with this finding, economists use a low interest rate to convert low risk savings into a present value and use a high interest rate to convert high risk savings into a present value. We consider past benefits of energy efficiency standards to be low risk, confident as we are that they have occurred. Less certain about the future, we consider future benefits of standards to be higher risk. Therefore, in this analysis we determine the present value of past savings using a low (3\%) interest rate and we determine the present value of future savings using a higher $(7 \%)$ discount rate.
} 
that estimated by DOE (Greening et al., 1997). One possibility is that the estimated manufacturing costs were reasonably accurate, but that competitive pressure prevented the manufacturers from passing all of the extra cost onto consumers. Another possibility is that manufacturers responded to the reality of standards by developing less expensive ways of meeting the standards relative to the engineering estimates made years in advance.

\section{References}

L. Greening, A. Sanstad, and J. McMahon, 1997. "Effects of Appliance Standards on Product Price and Attributes: An Hedonic Pricing Model," Journal of Regulatory Economics 11 (2), 181194. (LBNL-39739). 


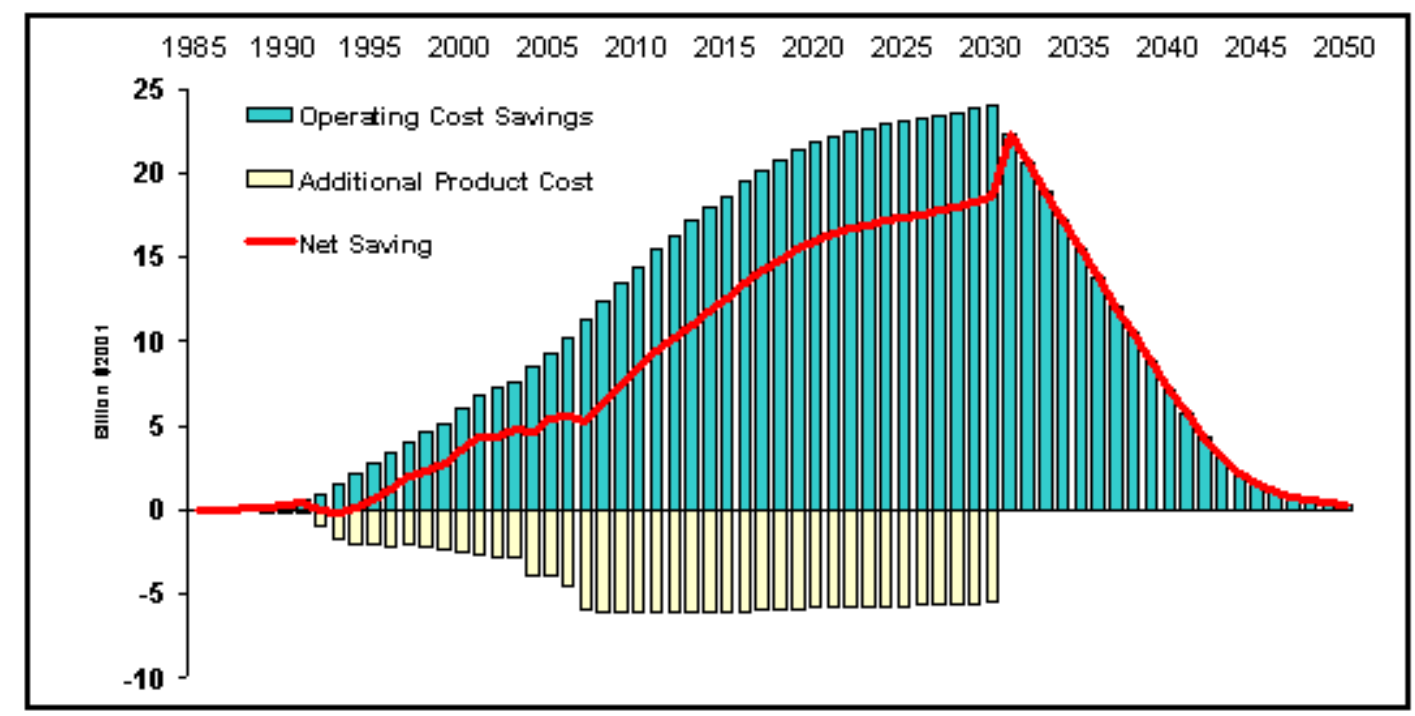

Figure 6.1 Annual Consumer Impacts of DOE Appliance Standards - All Products (Not Discounted)

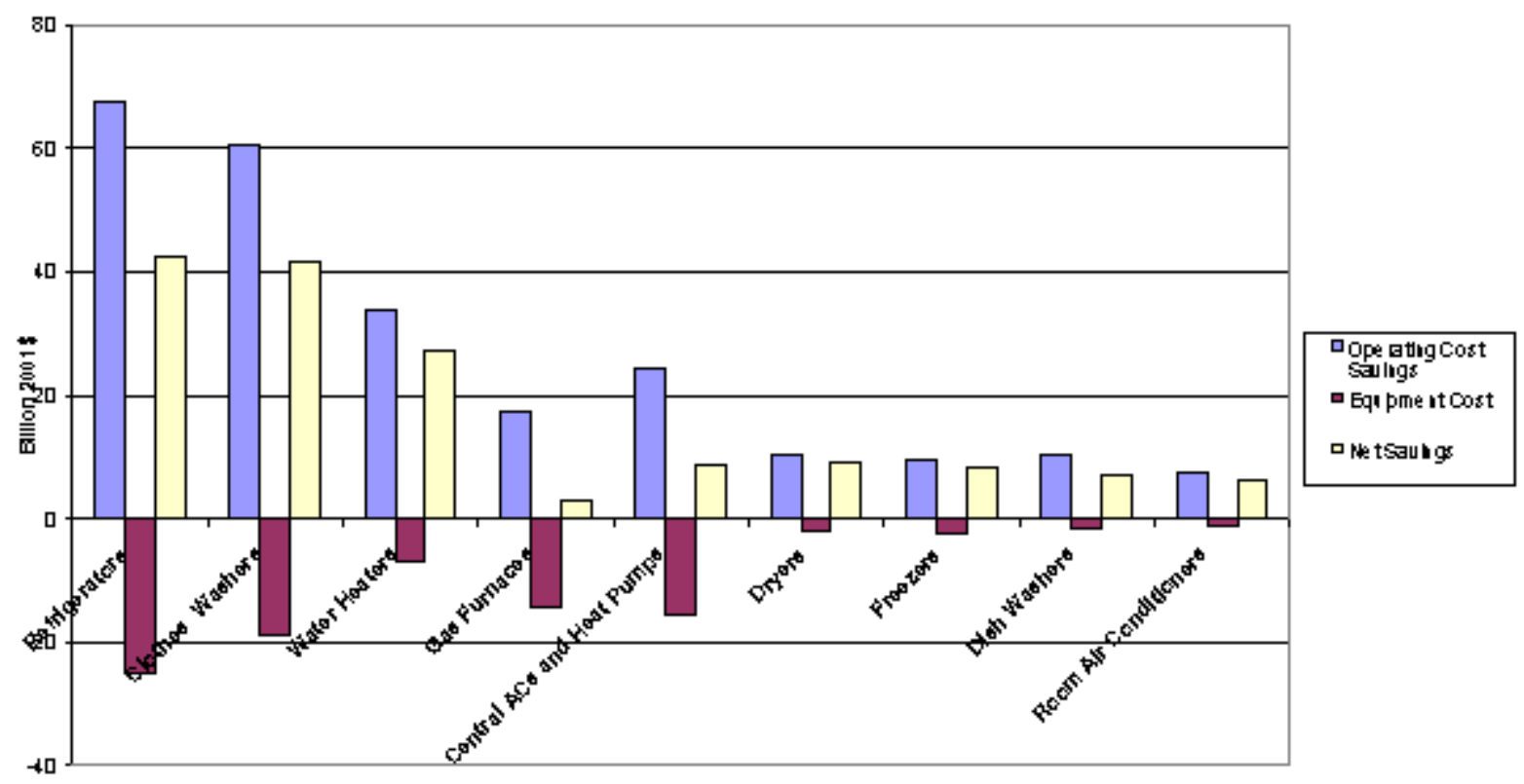

Figure 6.2 Present Value in 2001 of Cumulative Consumer Costs and Benefits from DOE Appliance Standards, 1987-2050 


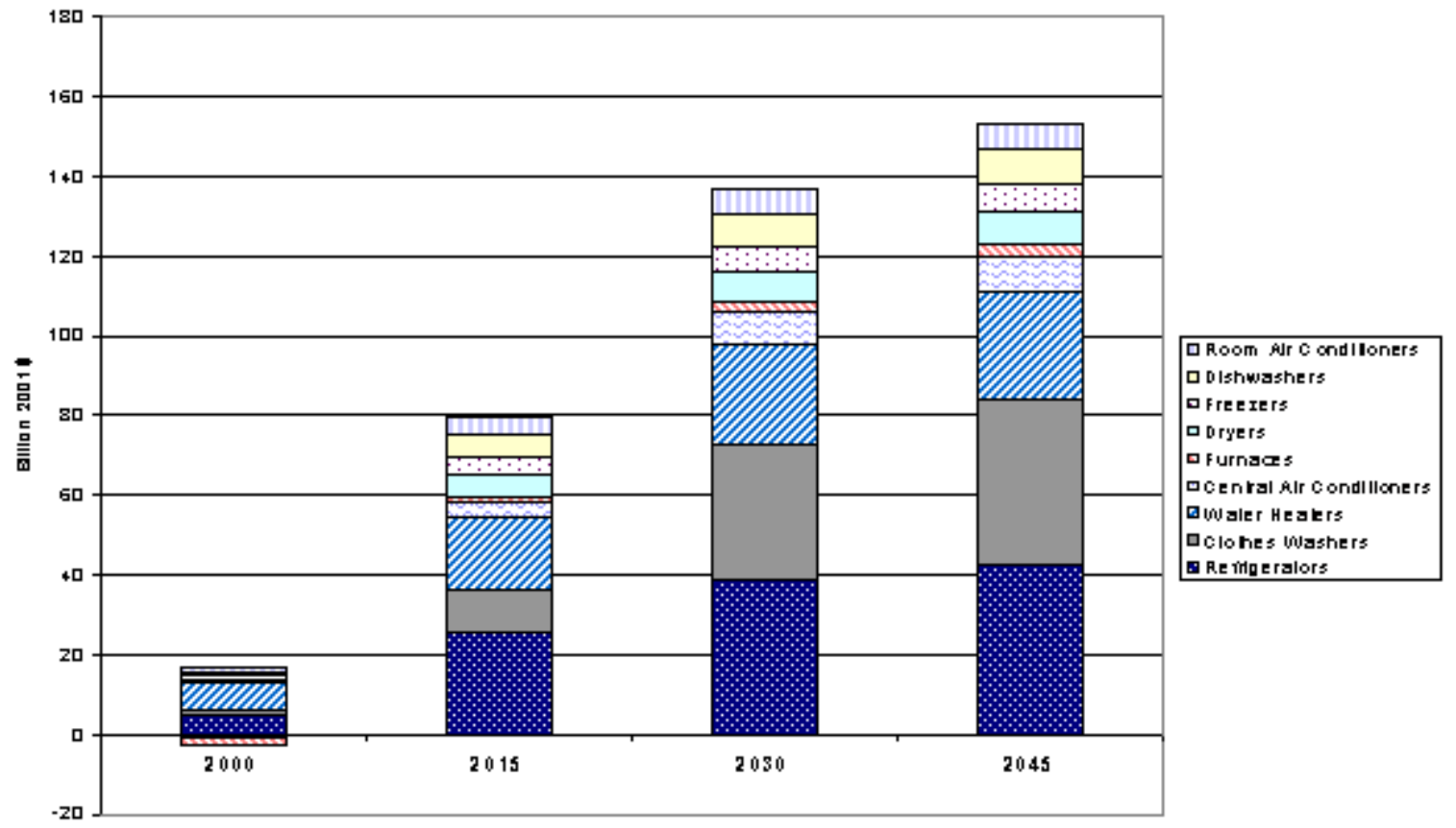

Figure 6.3 Net Present Value in 2001 of Cumulative Direct Consumer Benefits from DOE Appliance Standards from 1987 through Specific Years

Note: the negative value in 2000 reflects the fact that operating cost savings had not yet matched the extra equipment costs. 


\section{Environmental Emissions Reduction Due to Standards}

Reductions in carbon dioxide $\left(\mathrm{CO}_{2}\right)$ and nitrogen oxide $\left(\mathrm{NO}_{\mathrm{x}}\right)$ emissions due to DOE's appliance standards are based on the estimated savings in primary energy use for electricity generation and primary natural gas consumption. We derived average emissions factors in terms of million metric tons of carbon (MtC) per quad of primary energy for each year in the 1987-2050 period, using historic (EIA, 2001a) and projected (EIA, 2001b) data on total $\mathrm{CO}_{2}$ emissions from U.S. electricity generation, along with corresponding data on primary energy consumption by the power sector. For $\mathrm{NO}_{\mathrm{x}}$ emissions from electricity generation and from natural gas consumption, we used a single average emissions factor for all years.

Because emissions of $\mathrm{SO}_{2}$ from power plants are capped by clean air legislation, physical emissions of this pollutant from electricity generation will be only minimally affected by appliance standards. The maximum $\mathrm{SO}_{2}$ allowed by law will most likely still be produced.

Appliance standards also reduce emissions of mercury from coal-fired generation, but we are not aware of reliable emissions factors.

For electricity generation, the use of average emissions factors produces lower values for avoided emissions than would use of marginal factors, which reflect the type of power plants whose production would be cut back due to electricity conservation.

Figure 7-1 shows the annual reductions in $\mathrm{CO}_{2}$ emissions due to DOE's appliance standards. Without the standards, total projected $\mathrm{CO}_{2}$ emissions from the residential sector (including emissions associated with electricity use) in 2020 are $418 \mathrm{MtC}$. With the standards, the estimated value is $381 \mathrm{MtC}-9$ percent less. ${ }^{6}$ The reduction of $37 \mathrm{MtC}$ is equivalent to the $\mathrm{CO}_{2}$ released by typical annual operation of 28 million of today's average cars.

The annual reduction in $\mathrm{NO}_{\mathrm{x}}$ emissions due to standards in 2020 is 0.35 million tons, which is equivalent to around $5 \%$ of total current $\mathrm{NO}_{\mathrm{x}}$ emissions from U.S. electric utilities.

Figure 7-2 shows the cumulative reduction in $\mathrm{CO}_{2}$ emissions in the 1987-2050 period for each product standard.

Table 7-1 presents the cumulative reduction in emissions for all product standards combined.

To place an approximate economic value on the reductions in emissions, we relied on the estimates used by the National Research Council in its recent review of energy research at DOE (NRC, 2001). These ranges are $\$ 6$ to $\$ 11$ for a metric ton of carbon and $\$ 2,300$ to $\$ 11,000$ for a

\footnotetext{
${ }^{6}$ The "with standards" value is the total residential sector emissions in 2020 given in EIA's Annual Energy Outlook 2002. We derived the "without standards" value by adding our estimate of carbon reduction due to standards to the EIA projection, which nominally includes the impact of standards.
} 
metric ton of $\mathrm{NO}_{x}$. For $\mathrm{NO}_{x}$, we used a range of $\$ 2,300-\$ 4,600$ to account for the fact that emissions from power plants are less damaging than those from motor vehicles in urban areas. The present value of the cumulative reductions due to appliance standards in the study period (using the same method as for direct consumer benefits) amounts to $\$ 2.6-\$ 4.8$ billion for avoided $\mathrm{CO}_{2}$ emissions and \$10-20 billion for avoided $\mathrm{NO}_{\mathrm{x}}$ emissions.

Table 7-1. Reduction in Cumulative U.S. Emissions due to DOE's Appliance Standards

\begin{tabular}{|c|c|c|}
\hline $\begin{array}{c}\text { From 1988 } \\
\text { through: }\end{array}$ & $\begin{array}{c}\mathbf{C O}_{2} \\
(\mathrm{MtC})\end{array}$ & $\begin{array}{c}\mathbf{N O}_{\mathbf{x}} \\
(\mathrm{Mt})\end{array}$ \\
\hline 2000 & 61 & 0.62 \\
\hline 2015 & 423 & 4.21 \\
\hline 2030 & 954 & 9.29 \\
\hline 2050 & 1196 & 11.7 \\
\hline
\end{tabular}

\section{References}

Energy Information Administration (2001a). Annual Energy Review 2000, U.S. Department of Energy, Washington, D.C.

Energy Information Administration (2001b). Annual Energy Outlook 2002, U.S. Department of Energy, Washington, D.C.

National Research Council (2001). Energy Research at DOE: Was It Worth It?, National Academy Press, Washington, D.C. 


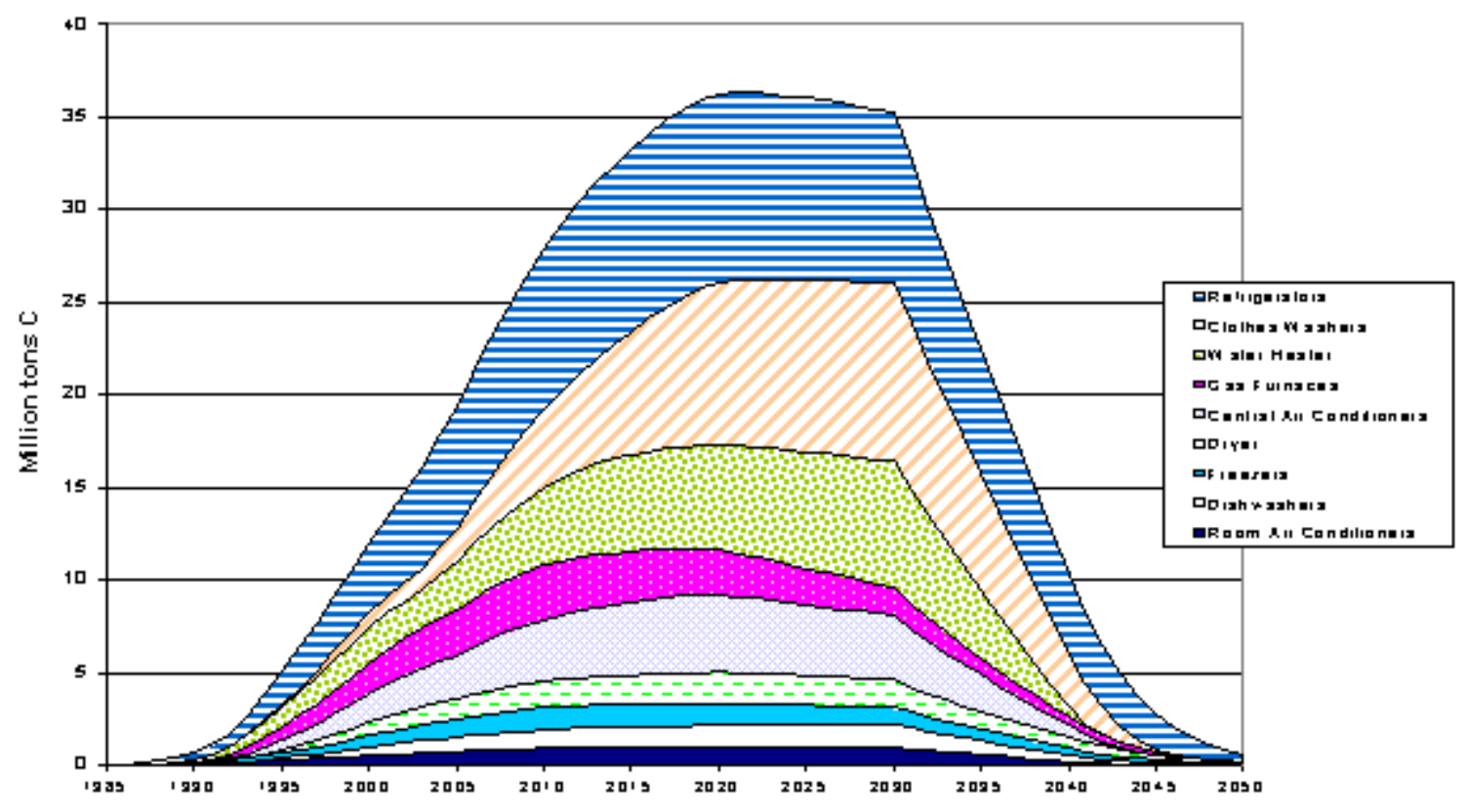

Figure 7-1. Annual $\mathrm{CO}_{2}$ Emissions Reduction from DOE Appliance Standards by Product

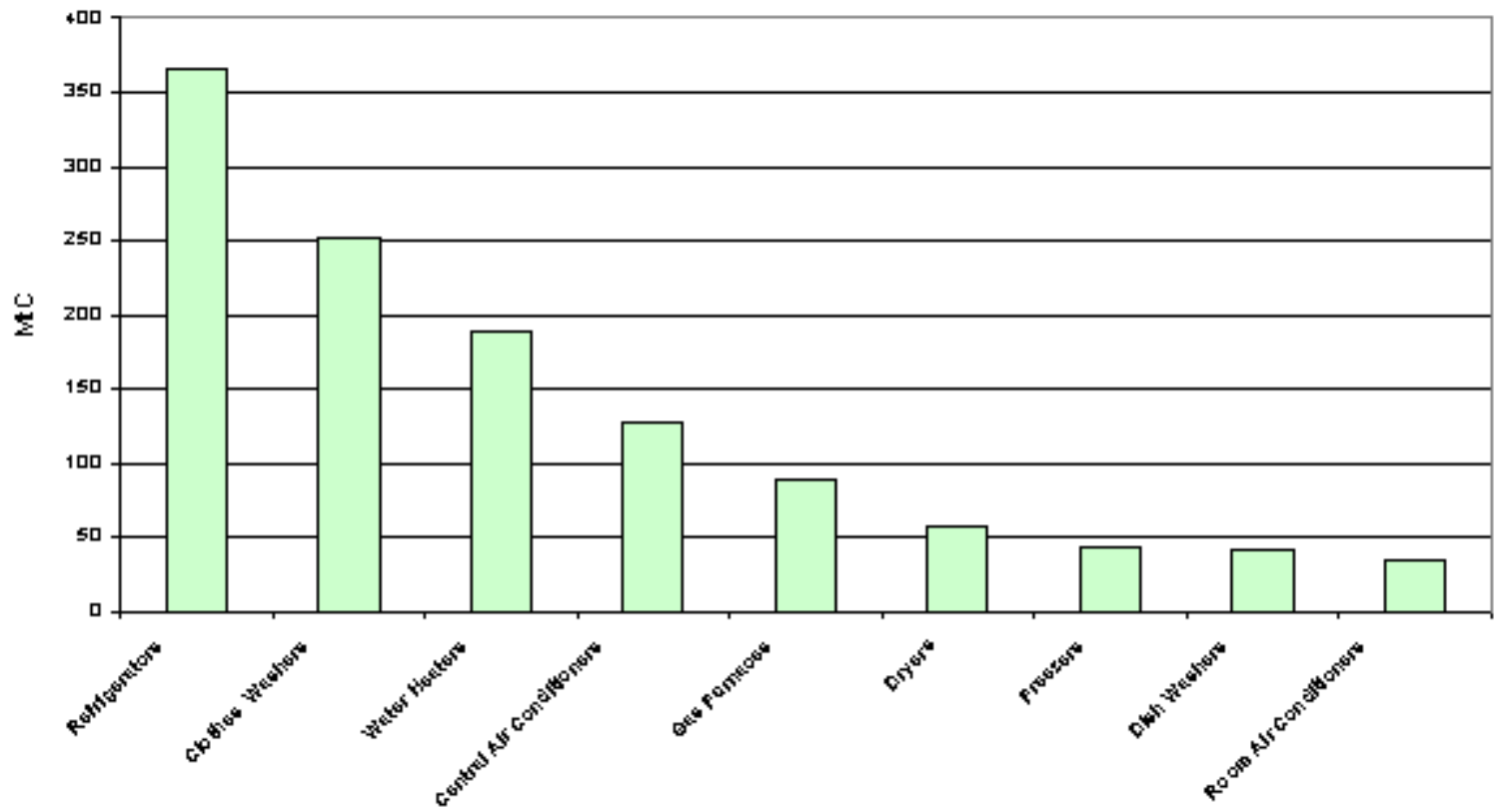

Figure 7-2. Cumulative $\mathrm{CO}_{2}$ Emissions Reduction from DOE Appliance Standards by Product in 1987-2050 Period 


\section{Sources of Uncertainty}

A measure of uncertainty applies to all of the variables used in this analysis. For example, future shipments may be higher or lower than expected, due to economic factors.

Perhaps the greatest uncertainty concerns the estimation of the baseline scenarios - what would have occurred in the absence of standards. Both technological and economic factors have contributed to energy efficiency trends in the past. Considering historical efficiency trends, and given the expectation of little long-run change in residential energy prices (see Annual Energy Outlook 2002), and the intensity of price competition in the appliance market, we believe that the baseline trends in efficiency improvement developed in this study are reasonable.

Another large source of uncertainty concerns the incremental cost to consumers of higher efficiency products. Real prices of these goods have tended to trend downward over time and the competitive nature of the market continues to exert downward pressure. As mentioned above, we believe that the future incremental price estimates used in this study (and in the TSDs) are more likely to be overstated than understated. So the costs associated with standards may be overestimated.

The benefits of standards may be underestimated in this report if future energy prices increase more than expected or if other factors (such as reduced emissions) are in future assigned some economic value. For some specific appliances, the marginal benefit may be greater than estimated here because the energy savings occur during peak demand periods.

\section{Conclusion}

We estimate that U.S. federal energy efficiency standards for residential appliances that became effective in the 1988-2001 period or will take effect by the end of 2007 will reduce residential primary energy consumption and $\mathrm{CO}_{2}$ emissions in 2020 by 8-9\% compared to the levels expected without any standards. The estimated absolute growth in residential primary energy consumption between 1990 and 2020 without standards is 10 quads. The standards reduce this growth to 8 quads.

Standards will have saved a cumulative total of 25-30 quads by the year 2015, and 60 quads by 2030. Including benefits starting in 1988, the estimated cumulative net present value of direct consumer benefits amounts to nearly $\$ 80$ billion by 2015 , and grows to $\$ 130$ billion by 2030 . The overall benefit/cost ratio of consumer impacts in the $1987-2050$ period is $2.75: 1$. The cost of DOE's program to establish and implement the standards has been in the range of \$200-250 million. 
In addition to consumer financial benefits, the standards will reduce emissions of $\mathrm{CO}_{2}$ and $\mathrm{NO}_{\mathrm{x}}$ by considerable amounts.

\section{APPENDIX 1 Technical Support Documents for DOE Residential Energy Efficiency Standards}

1. U.S. Department of Energy-Office of Codes and Standards, Technical Support Document: Energy Efficiency Standards for Consumer Products: Room Air Conditioners, Water Heaters, Direct Heating Equipment, Mobile Home Furnaces, Kitchen Ranges and Ovens, Pool Heaters, Fluorescent Lamp Ballasts \& Television Sets, 1993. Washington, DC. Report No. DOE/EE-0009.

2. U.S. Department of Energy-Office of Codes and Standards, Technical Support Document: Energy Efficiency Standards for Consumer Products: Refrigerators, Refrigerator-Freezers, and Freezers, including Environmental Assessment and Regulatory Impact Analysis, July, 1995. Washington, DC. Report No. DOE/EE-0064. <http://www.osti.gov/bridge/product.biblio.jsp?osti_id=90266>

3. U.S. Department of Energy-Office of Codes and Standards, Technical Support Document For Energy Conservation Standards for Room Air Conditioners, September, 1997. Washington, DC. Docket Numbers EE-RM-90-201 \& EE-RM-93-801-RAC.

4. U.S. Department of Energy-Office of Codes and Standards, Technical Support Document: Energy Efficiency Standards for Consumer Products: Residential Central Air Conditioners and Heat Pumps, 1999. Washington, DC.

<http://www.eren.doe.gov/buildings/codes_standards/reports/central_air_tsd/index.htm>

5. U.S. Department of Energy-Office of Building Research and Standards, Technical Support Document: Energy Efficiency Standards for Consumer Products: Residential Water Heaters, 2000, U.S. Department of Energy. Washington, DC. Report No. LBNL47419.

<http://www.eren.doe.gov/buildings/codes_standards/reports/waterheater/index.html>

6. U.S. Department of Energy-Office of Building Research and Standards, Final Rule Technical Support Document (TSD): Energy Efficiency Standards for Consumer Products: Clothes Washers, 2000, U.S. Department of Energy. Washington, DC. Report No. LBNL-47462.

<http://www.eren.doe.gov/buildings/codes_standards/reports/cwtsd/index.html> 
7. U.S. Department of Energy-Office of Building Research and Standards, Technical Support Document: Energy Efficiency Standards for Consumer Products: Residential Central Air Conditioners and Heat Pumps, 2000, U.S. Department of Energy. Washington, DC. Report No. LBNL-47463.

<http://www.eren.doe.gov/buildings/codes_standards/reports/cac_hp_tsd/index.html> 